\title{
Le catéchisme et la machine à coudre. Cartes postales missionnaires et travail féminin en Afrique de l'Ouest (1920-1940)
}

The catechism and the sewing machine. Missionary postcards and women's work in West Africa

Julien Bondaz

\section{OpenEdition} Journals

Édition électronique

URL : https://journals.openedition.org/itti/688

DOI : $10.4000 /$ itti.688

Éditeur

Université de Poitiers

Référence électronique

Julien Bondaz, «Le catéchisme et la machine à coudre. Cartes postales missionnaires et travail féminin en Afrique de l'Ouest (1920-1940) », Images du travail, travail des images [En ligne], 6-7 | 2019, mis en ligne le 01 février 2019, consulté le 21 septembre 2021. URL : http://journals.openedition.org/ itti/688 ; DOl : https://doi.org/10.4000/itti.688

Ce document a été généré automatiquement le 21 septembre 2021.

Images du travail, travail des images 


\section{Le catéchisme et la machine à coudre. Cartes postales missionnaires et travail féminin en Afrique de l'Ouest (1920-1940)}

The catechism and the sewing machine. Missionary postcards and women's work in West Africa

Julien Bondaz

1 Justine a été l'une des vedettes de l'Exposition coloniale de 1931. Alors âgée de dix ans, elle était la benjamine des quinze femmes "soudanaises " ayant accompagné à Paris deux des Sœurs Blanches de la mission de Ouagadougou (Haute-Volta), pour faire la propagande de l'œuvre missionnaire en Afrique de l'Ouest ${ }^{1}$. Chaque jour, dans le pavillon de l'Afrique Occidentale Française (AOF), ces jeunes femmes assuraient une démonstration de cardage, de filage et de tissage haute-laine, spécialité des ouvroirs de Ouagadougou et de Ségou (Soudan français). Outre les produits ainsi réalisés, des cartes postales mettant en scène le travail des religieuses dans les colonies ou représentant le pavillon des Missions étaient également proposées aux visiteurs, pour vingt centimes. L'Exposition coloniale de 1931 a ainsi constitué l'un des temps forts de la diffusion de ces cartes postales missionnaires. Le jeune âge de Justine en fit l'une des meilleures vendeuses, à tel point que, parmi la série de vingt cartes consacrées à ces quinze "Soudanaises » et rassemblées en carnet, la première la représente, faisant face au photographe - et donc au récepteur de l'image. Comme aux visiteurs, elle lui tend une carte postale, et tient dans son autre main une corbeille pleine d'images. 
Image 1. Carte postale, " Justine vendant des cartes postales »

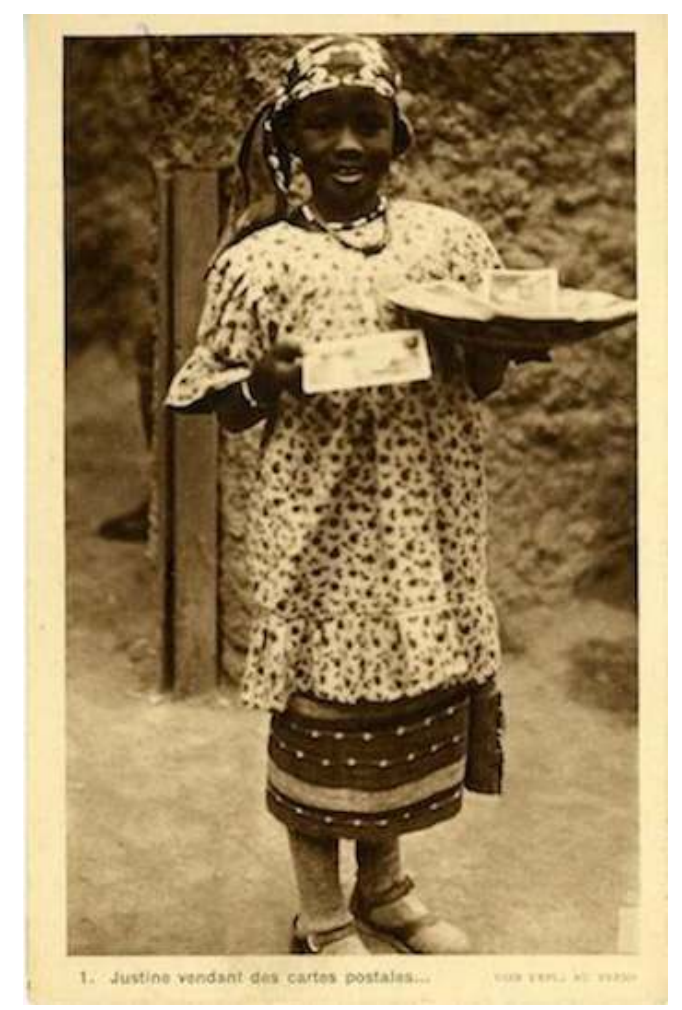

Exposition Coloniale de Paris, 1931, Sœurs Missionnaires de Notre-Dame d'Afrique, St-Charles Édition G.-L. Arlaud, Lyon (http://www.cparama.com/forum/paris-exposition-colonialeinternationale-1931-t5660.html)

2 Une telle mise en abyme est révélatrice : Justine vendant des cartes postales se retrouve à vendre sa propre image aux visiteurs de l'Exposition. L'enjeu n'est alors pas de tirer puis de commercialiser un portrait de jeune femme répondant au principe de typicité ou à l'esthétique de l'érotisation du corps féminin caractérisant les cartes postales coloniales - de ce point de vue, les images féminines proposées par les cartes postales missionnaires se construisent en opposition à l'imaginaire de la « lubricité de la femme noire" des autres cartes postales coloniales (Belmenouar et Combier, 2007, 72) 2 . L'objectif est plutôt de témoigner de la transformation de Justine, presqu'une enfant encore, en agent de la propagande coloniale et de son inscription individuelle et singulière dans l'économie de la circulation des images missionnaires - une deuxième carte postale la représente de nouveau seule, dans une situation inversée de sollicitation, voire de mendicité. 
Image 2. Carte postale, « Justine »

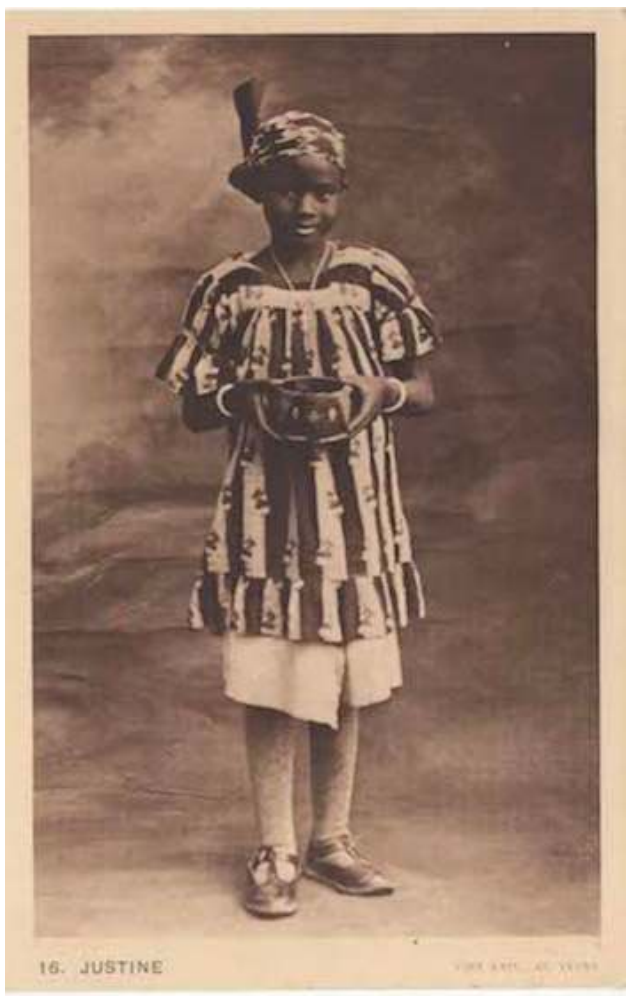

Exposition Coloniale de Paris, 1931, Sœurs Missionnaires de Notre-Dame d'Afrique, St-Charles Édition G.-L. Arlaud, Lyon (collection de l'auteur)

3 Le travail de la jeune fille révèle ici celui que ses consœurs accomplissent dans le pavillon de l'AOF en cardant, en filant et en tissant la laine sous les yeux des visiteurs : moins que les produits de leur travail, c'est le fait même qu'elles travaillent à l'œuvre missionnaire, en produisant et en commercialisant des objets et des images, qui importe.

4 La quatrième carte postale du carnet inauguré par le portait de Justine en vendeuse de cartes postales en témoigne parfaitement. 
Image 3. Carte postale, « Au travail »

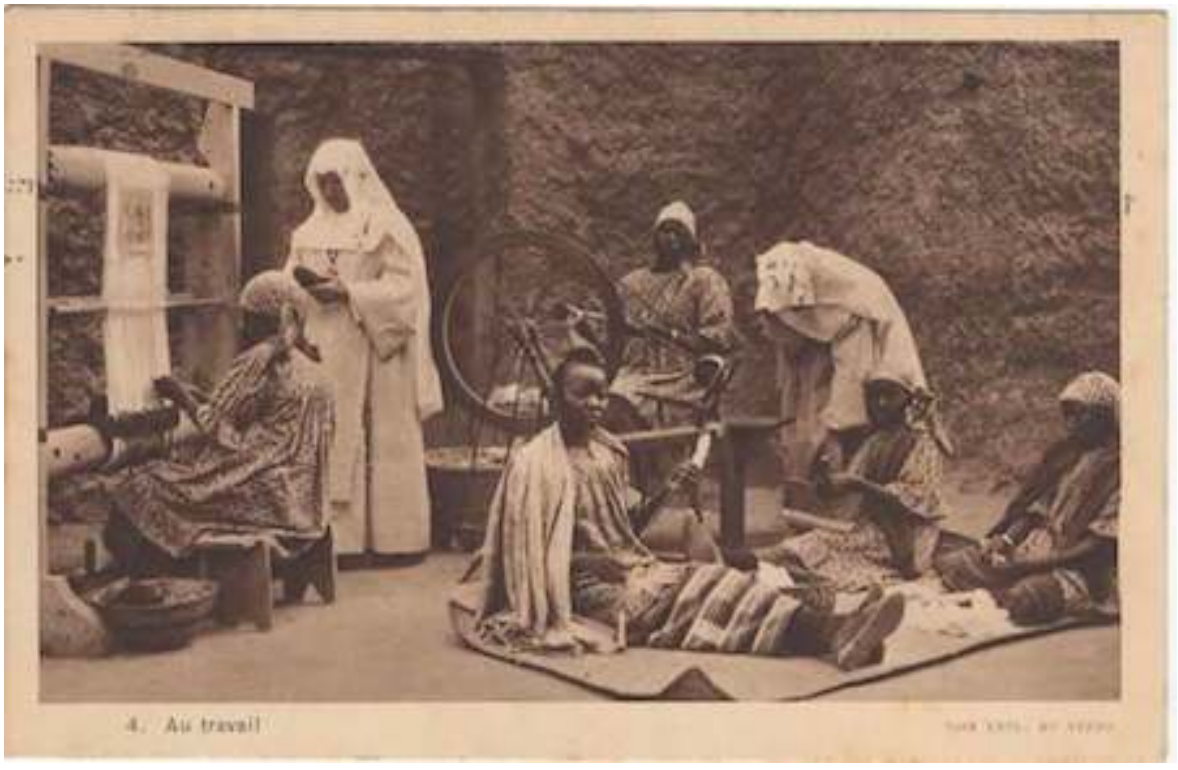

Exposition Coloniale de Paris, 1931, Sœurs Missionnaires de Notre-Dame d'Afrique, St-Charles Édition G.-L. Arlaud, Lyon (collection de l'auteur)

5 On y voit les trois étapes de la confection de tapis (cardage, filage et tissage), assurées par cinq des femmes « soudanaises » assistées par les deux Sœurs blanches. La légende, lacunaire, est ambiguë: «Au travail». Elle désigne évidemment le travail des cinq femmes africaines, et sans doute leur mise au travail - la valeur descriptive de la légende pouvant s'entendre comme valeur impérative. Mais elle désigne également l'activité missionnaire elle-même, le travail des deux religieuses, l'une tenant la navette du métier à tisser, l'autre se penchant sur l'une des cardeuses, promulguant peut-être consignes ou conseils.

6 L'importance de la thématique du travail féminin s'explique par un contexte missionnaire qui fait de la conversion des femmes "indigènes" un moyen de pénétration dans les familles. Comme le pouvoir colonial à la même époque (Barthélémy 2002 et 2010, Barthélémy et Jézéquel, 2007), les missionnaires sont convaincus que leur entreprise d'évangélisation, pour être durable, doit passer par la formation de bonnes épouses, mères de famille et ménagères et que cette formation, pour être efficace, doit être assurée par des femmes. L'entreprise missionnaire et coloniale repose donc sur le brouillage de la séparation entre le ménage et le travail, entre l'espace domestique et l'unité de production. Dans cette perspective, les missionnaires encouragent alors «l'apostolat de la femme par la femme " (Anonyme, 1925, 661)3. Sœur Marie-André du Sacré-Cœur, qui a mené des recherches sur la condition des femmes en Afrique de l'Ouest dans les années 1930, considérait ainsi que "c'est par la femme que nous ferons la conquête morale de toutes ces populations " $(1939,255)^{4}$. Conforme aux conceptions chrétiennes du travail de l'époque, le travail féminin se retrouve doté d'une double fonction de moralisation et de domestication. Dans un ouvrage paru à l'occasion de l'Exposition coloniale, Paul Lesourd, l'un des premiers historiens des missions catholiques, résumait :

«Le travail exerce sur tous ceux qui s'y livrent une action moralisatrice qui ne se remarque nulle part autant que dans les milieux indigènes où le farniente a tant de charmes et déchaîne tant de lamentables licences. C'est en outre un moyen très 
efficace de donner à la femme, un rôle plus convenable dans la famille et dans la société. » (Lesourd, 1931b, 77)

7 Cette conception du travail féminin fait apparaître en creux un portrait stéréotypé et dépréciatif des femmes ouest africaines (taxées d'oisiveté, d'immoralité et d'inconvenance). Une telle valeur civilisatrice du travail féminin repose en outre sur une ambivalence : présenté par les missionnaires comme un outil d' "émancipation », d' " évolution ", de " relèvement " ou de " libération » des femmes africaines (comme $\mathrm{du}$ reste le culte marial) ${ }^{5}$, le travail leur assigne dans le même temps un rôle dans l'économie du projet impérialiste, une place dans des rapports de domination où s'articulent, de manière complexe, le genre, la classe et la race, ainsi que l'a montré Shula Marks (1994) dans un contexte en partie similaire.

Cette ambivalence des rencontres missionnaires féminines a été déjà largement présentée. En 1993, partant du constat que «missionnaire était un nom masculin [et qu']il dénotait un acteur masculin, une action masculine, une sphère de services masculine " (Cunningham, 1993, 89) ${ }^{6}$, Fiona Bowie, Deborah Kirkwood et Shirley Ardener ont souhaité combler l'occultation des femmes dans l'histoire des missions catholiques et protestantes (Bowie, Kirkwood et Ardener, 1993). La même année, la publication de la thèse d'Élisabeth Dufourq ouvrait une perspective identique aux chercheuses et chercheurs francophones (Dufourq, 1993). De nombreux travaux ont depuis été conduits sur le rôle des femmes dans l'entreprise missionnaire, en particulier dans une optique d'histoire du genre (Huber et Lutkehaus, 1999 ; Rogers, 2009 ; Prevost, 2010). En 2010, un numéro spécial de la revue Histoire et missions chrétiennes, dirigé par Sarah A. Curtis («L'autre visage de la mission : les femmes ») 7 , puis en 2014, celui de la revue Histoire, Monde et Cultures religieuses, sous la direction de Katrin Langewiesche, ont permis d'ouvrir d'autres perspectives encore. Ces nombreux travaux pointent tous le manque de sources ou l'invisibilité des femmes dans de trop nombreuses archives missionnaires. C'est particulièrement vrai pour la période de l'entre-deux-guerres, la plupart des écrits missionnaires étant masculins et les quelques ouvrages écrits par des religieuses étant souvent publiés de manière anonyme (voir par exemple Anonyme 1931 et 1935).

9 À la même époque cependant, la production et la diffusion de cartes postales missionnaires accordent une grande place aux religieuses. Alors même que, pour l'histoire de la carte postale, l'entre-deux-guerres est une période " de relâchement, tant sur le plan quantitatif que sur celui de l'inspiration " (Tirefort, 2009, 305) ${ }^{8}$, les cartes postales missionnaires connaissent pour leur part un véritable essor, qui coïncide avec une période où les religieuses, peu représentées jusque-là dans l'imagerie missionnaire, accèdent de plus en plus à la visibilité : « la femme missionnaire permet [alors] de marquer l'aspect pacifique et humanitaire de la présence française » (RaisonJourde, 1993, 50). De nombreuses cartes postales sont éditées qui montrent des religieuses blanches parmi des femmes africaines, formant avec elles des groupes féminins censés dépasser les rapports de domination et les différences culturelles et rejetant hors-champ les présences masculines. De telles cartes postales donnaient à voir une forme de solidarité féminine construite indépendamment des sphères d'activités masculines (alors même que la plupart des photographies de l'époque ont sans doute été prises par des missionnaires masculins) ${ }^{9}$. Les situations d'apprentissage et de travail étaient, en particulier, envisagées comme des expériences collectives réunissant sœurs blanches et femmes africaines. Un lien visuel est établi entre communauté laborieuse et communauté confessionnelle, la valorisation religieuse du 
travail se révélant centrale dans l'entreprise missionnaire. Le travail est ainsi l'un des lieux privilégiés de rencontre entre religieuses et femmes ouest africaines.

Ces rencontres missionnaires peuvent être étudiées à une double échelle, celle, locale, des interactions quotidiennes sur le territoire des missions, qui invite à analyser l'imbrication des processus d'évangélisation et de professionnalisation, et celle, globale, de la transposition des normes religieuses et du modèle du travail féminin. La circulation et l'appropriation des idéologies, des formes de croyance, des modèles éducatifs et moraux ne doit d'ailleurs pas occulter celles des techniques et des outils de production, dont la machine à coudre fournit à coup sûr, à l'époque, un cas exemplaire. De ce point de vue, les cartes postales missionnaires forment des archives visuelles d'autant plus intéressantes qu'elles rendent compte de cette double échelle. En tant que photographies, elles sont présentées comme des témoignages visuels de situations concrètes d'interactions, d'environnements techniques, de présences corporelles - la place accordée au corps permettant précisément de caractériser le travail féminin (Perrot, 1978b, 198). Comme images de propagande produites à destination des Français métropolitains et largement diffusées, elles sont censées rendre compte de l'efficacité du transfert de ces normes et de ces modèles. C'est sous ce double aspect que les cartes postales missionnaires peuvent fournir des éléments pour l'analyse des redéfinitions des identités féminines dans le contexte des rencontres missionnaires de l'époque coloniale, notamment autour de ces différents champs d'activité que sont le catéchisme, l'éducation ménagère, les travaux manuels et les pratiques de soin ${ }^{10}$.

\section{Cartes postales en série}

11 Malgré la présence de plusieurs sociétés missionnaires concurrentes en Afrique de l'Ouest ${ }^{11}$, un effet d'unité dans les cartes postales s'observe qui justifie d'étudier les images du travail féminin produites au niveau de la sous-région. Cet effet s'explique par le costume peu distinctif des missionnaires et par l'imprécision des légendes des images (Hugon, 1997, 216), mais aussi par le privilège accordé au portrait de groupe et par l'anonymat qu'il induit - Justine fait de ce point de vue figure d'exception. L'étude des cartes postales missionnaires est néanmoins confrontée à des logiques plurielles de classification.

12 La première est celle des collectionneurs, des conservateurs ou des archivistes qui ont en charge leur conservation ou qui les étudient. On trouve d'abord des cartes postales dans les archives des congrégations missionnaires qui les ont éditées : la logique est ici celle du découpage des territoires concernés par congrégations religieuses ou des concurrences entre congrégations au sein d'un même territoire - c'est notamment le cas, au Sénégal, entre les Sœurs Bleues de Castres et les Sœurs de Saint-Joseph de Cluny. Les Cuvres Pontificales Missionnaires (Lolom, 2012) possèdent également un fonds iconographique important. Les cartes postales présentant l'activité des instituts féminins se retrouvent en outre souvent mêlées à celles qui concernent les instituts masculins. La logique des archives nationales des anciennes colonies repose pour sa part sur un principe territorial : les cartes postales missionnaires sont rassemblées avec les autres cartes postales de la période coloniale, formant ainsi une sorte de sousensemble.

13 Ce principe territorial est également celui qui prévaut chez nombre de collectionneurs privés, qui se spécialisent sur une région (l'Afrique de l'Ouest dans son ensemble, par 
exemple) ou un pays en particulier et ne distinguent pas, dans leurs pratiques, les motifs missionnaires et les autres. De nombreux collectionneurs privés valorisent leurs collections et le travail de documentation qu'ils accomplissent à leur sujet au sein d'associations (l'association Images \& Mémoires a notamment fédéré des travaux d'une grande richesse ${ }^{12}$ ) ou sur internet (voir par exemple le site "Images du passé en Afrique de l'Ouest $\left.{ }^{13}\right)$.

Les logiques actuelles de classification rendent imparfaitement compte de celles des éditeurs de ces cartes à l'époque coloniale. L'importance accordée aux images par les missionnaires expliquait alors l'engouement pour la photographie, qui permettait d'illustrer les nombreux ouvrages et revues édités par les différentes congrégations. Un petit nombre de photographies ont ainsi été utilisées à la fois comme illustrations et comme cartes postales (avec des choix de cadrage souvent différents). Dans le premier cas, elles trouvaient une part de leur signification dans le texte qu'elles accompagnaient, tandis que dans le second, elles fonctionnaient de manière plus autonome, la légende ne fournissant que peu d'éléments contextuels. Les cartes postales étaient, cependant, vendues par carnets de dix, parfois de douze ou de vingt, et l'ordre de la série était décidé par les maisons-mères des missionnaires. L'enchaînement des vues était conçu comme un récit visuel s'organisant en triptyque : " les missionnaires au travail ", « le paganisme comme un monde sauvage ", « scènes de la vie quotidienne » (Raison-Jourde, 1993, 53-54) ${ }^{14}$.

15 Ces carnets pouvaient être achetés dans différents lieux (auprès des maisons mères ou de l'CEuvre de Propagation de la Foi, à l'occasion de ventes organisées par les patronages, de foires ou d'expositions...). Les cartes postales étaient donc disponibles dans les colonies concernées, et plus largement dans les différentes colonies où la congrégation s'était implantée, ou, plus souvent, achetées directement en métropole. Elles forment ainsi des archives "cosmopolites » (Vokes, 2010). Une telle circulation avait pour conséquence qu'une même carte postale devait être compréhensible dans deux contextes de réception distincts - sans parler des distances géographiques et culturelles. L'acheteur (premier récepteur) la découvrait au sein d'une série d'autres images qui lui conférait une fonction narrative et lui assignait une place dans un album d'images, avant de la détacher pour l'écrire et l'envoyer. Le destinataire de la carte postale (second récepteur) la recevait pour sa part comme une image unique, indépendante de tout contexte explicatif, narratif ou visuel. La carte postale gagnait ainsi une autonomie rendant rétrospectivement problématique l'interprétation des significations qui lui étaient attribuées. Cependant, de nombreuses cartes n'ont pas circulé, notamment parce qu'elles étaient déjà collectionnées à l'époque, soit comme image autonome soit non détachées du carnet qui leur conférait une certaine signification.

16 Les divers carnets rendent compte des classifications en vigueur à l'époque de production des images et des échelles géographiques différentes sur lesquelles elles reposent. Certains d'entre eux présentent le travail missionnaire tel qu'il se déploie dans un territoire spécifique, les frontières coloniales servant de cadre géographique à la série. D'autres proposent une thématique qui dépasse les logiques territoriales en traitant de la présence missionnaire à travers le monde (carnet de dix cartes «Les catéchistes dans le monde », édité par l'œuvre Pontificale de la Propagation de la Foi, par exemple). D'autres enfin constituent des panoramas de l'ensemble des activités de la congrégation éditrice à travers l'Afrique. Les Sœurs Missionnaires de Notre-Dame 
d'Afrique éditent par exemple plusieurs carnets sous le titre générique "En Afrique ", proposant à chaque fois une série de dix cartes, chacune étant numérotée. La quatrième, consacrée au Soudan français et à la Haute-Volta, s'ouvre sur la vue d'un village ("Arrivée dans un village »), puis des portraits de femmes, d'enfants ou de vieillards «soudanais" alternent avec des photographies mettant en scène les différents aspects du travail des religieuses (quatre cartes respectivement dédiées au catéchisme, au dispensaire, à l'ouvroir et à l'école, dont on verra qu'ils sont centraux dans la propagande missionnaire). La série se termine sur le portrait d'un groupe d'enfants habillés en blanc, encadrés par leur famille, et légendée ainsi : «Sur l'instante demande du Baloum-Naba, grand chef de Province encore païen, baptême de ses 14 plus jeunes enfants». Cette dernière image du carnet figure ainsi l'aboutissement de l'activité missionnaire présentée dans celles qui la précèdent : la conversion est le but ultime du travail des religieuses.

Autre exemple, les Sœurs Missionnaires de Notre-Dame des Apôtres ont édité plusieurs carnets de dix cartes consacrés chacun à l'une des colonies dont elles avaient la charge.

Image 4. Couverture d'un carnet de cartes postales

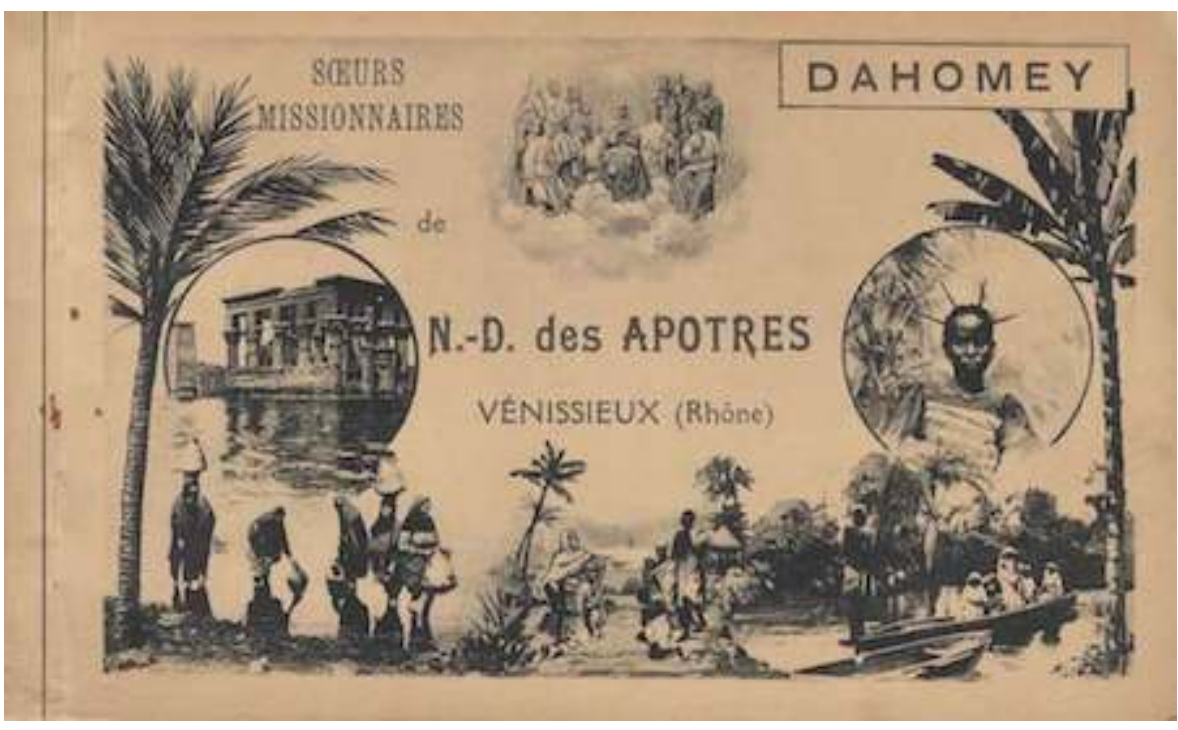

Série « Dahomey », sans date, Sœurs Missionnaires de Notre-Dame des Apôtres

(collection de l'auteur)

Dans le carnet présentant le Dahomey, deux vues animées («Un coin de lagune » et "Un marché ») voisinent avec des portraits de groupe ("enfants", "jeunes filles chrétiennes " et "vieillards ») et des témoignages visuels du travail des religieuses (leçons de catéchisme et de travail manuel). Dans celui dédié au Togo, les religieuses sont présentes sur chacune des cartes, dont deux sont des vues de l'école ménagère de Lomé. La thématique du travail se trouve ainsi représentée dans plusieurs carnets de l'époque et dans diverses collections actuelles. Cette transversalité - comme l'absence des témoignages écrits - rend complexe l'analyse de la réception des cartes. Elle révèle cependant une intention partagée par les différents éditeurs, qui accordent une place centrale au travail dans les images de propagande missionnaire. Durant l'entre-deuxguerres, travail des images missionnaires et images du travail féminin sont étroitement liés. 


\section{Catéchisme et travail des images} missionnaire : la tournée apostolique et, surtout, la leçon de catéchisme. La figuration des religieuses en tournée permet d'insister sur leur immersion dans la vie quotidienne des populations auprès de qui elles vivent. Sur une carte postale éditée par les Missions d'Afrique, par exemple, deux religieuses observent un groupe de femmes en train de piler du mil, debout à côté d'elles - par contraste avec l'homme et les enfants assis devant ${ }^{15}$.

Image 5. Carte postale, « Soudan français. Pilage du Mil »

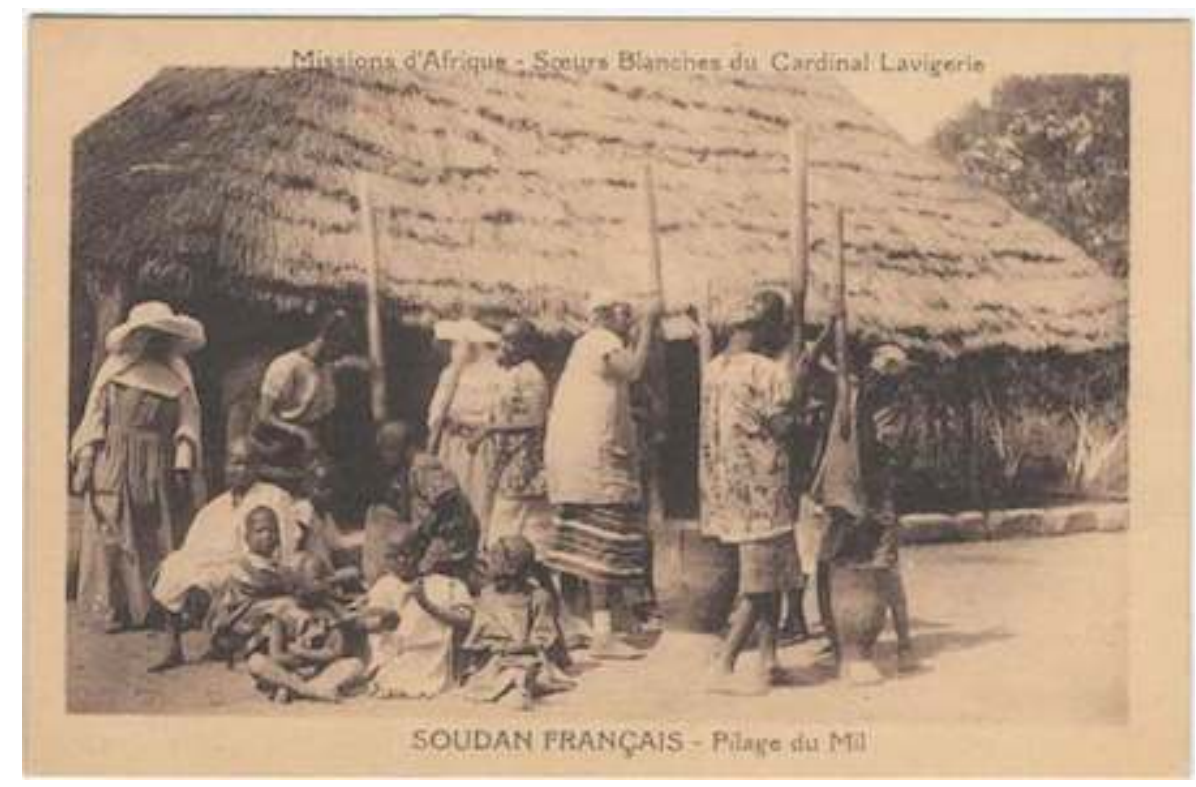

Sans date, Sœurs Missionnaires de Notre-Dame d'Afrique

(collection de l'auteur)

21 La figure de la pileuse de mil constitue à l'époque l'un des clichés de l'imagerie coloniale (Belmenouar et Combier, 2007, 78). Dans la préface que Georges Hardy rédige pour le livre que Sœur-Marie André du Sacré-Cœur consacre aux femmes africaines, il dresse le portrait de l'auteure «toute blanche au milieu de ses amies pileuses de mil » (Hardy, 1939, 9). L'expression signale un effet de contraste : les femmes forment un groupe, seule la couleur de leur peau signale leur différence. L'immersion des religieuses dans la vie des femmes se traduit cependant, visuellement (sur la carte postale qui nous intéresse), par leur position en retrait, en arrière du groupe et, pour l'une des deux, sur le côté - l'autre d'ailleurs a le visage caché par l'extrémité d'un 
pilon. C'est un dispositif visuel récurrent des cartes postales missionnaires : la présence des religieuses dans l'image est à la fois répétée et discrète - à la façon des figurations des donateurs ou des commanditaires dans nombre de peintures religieuses de la Renaissance. Elle vaut comme indice de l'activité missionnaire (de la qualification missionnaire de la carte postale, donc ${ }^{16}$ ) et comme délégation d'une certaine autonomie, visuelle au moins, aux groupes ciblés par cette activité.

Les nombreuses cartes postales consacrées aux leçons de catéchisme témoignent bien de cette bivalence : elles donnent généralement à voir les catéchumènes de face, tandis que la religieuse se retrouve de profil, sur l'un des côtés de l'image.

Image 6. Carte postale, « Soudan. Ségou. L'enseignement du catéchisme »

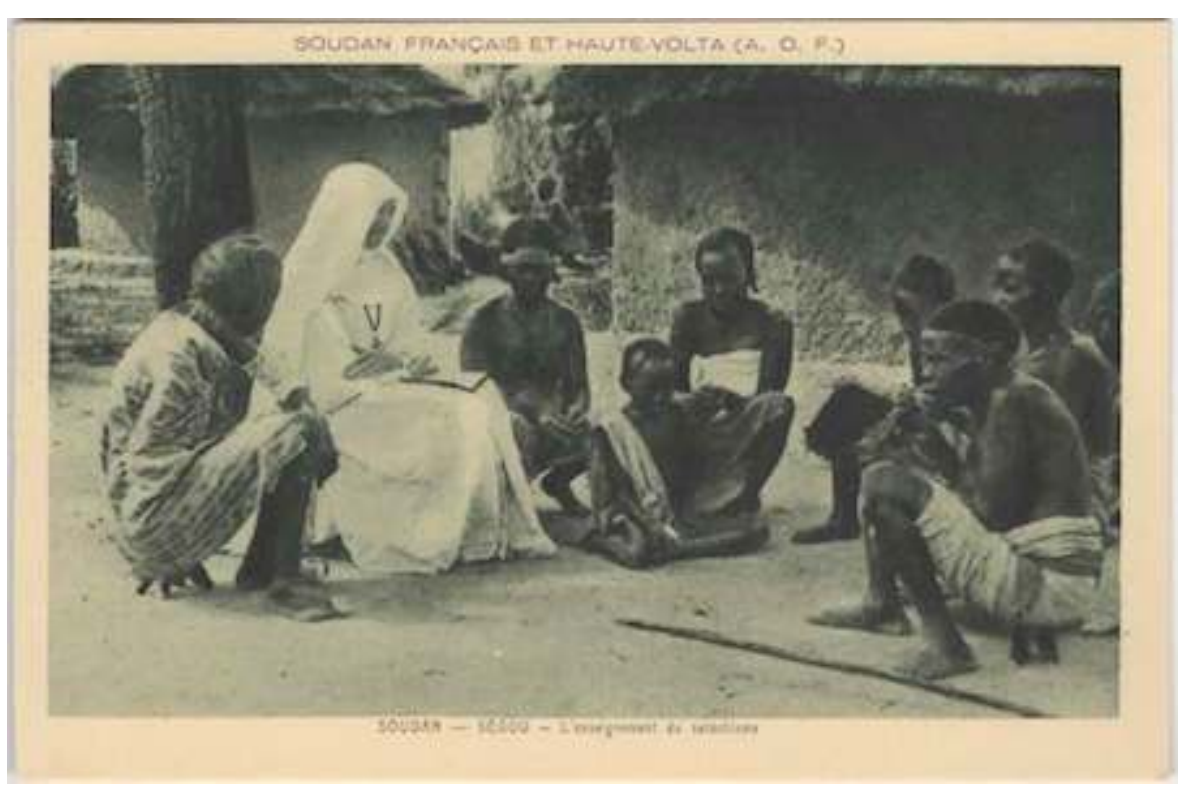

Sans date, Sœurs Missionnaires de Notre-Dame d'Afrique, St-Charles

Édition G.-L. Arlaud, Lyon (collection de l'auteur) 
Image 7. Carte postale, « Dahomey. Cours catéchisme aux adultes »

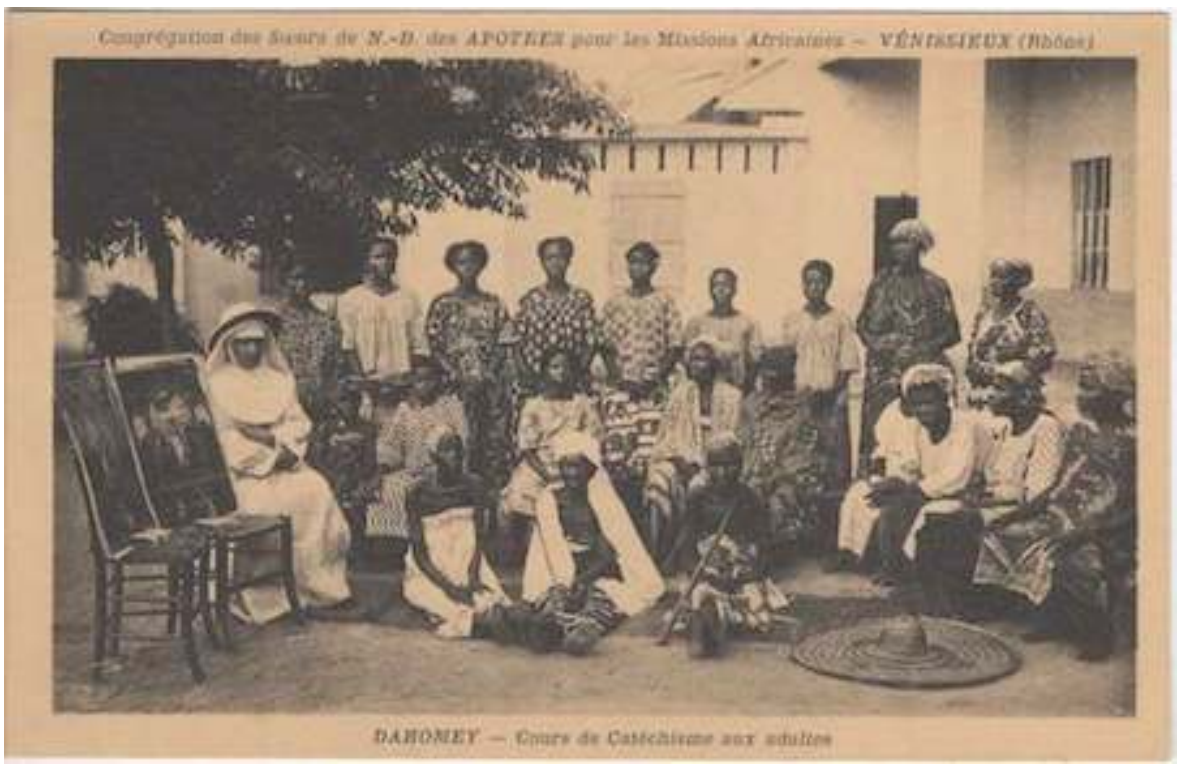

Sans date, Sœurs Missionnaires de Notre-Dame des Apôtres (collection de l'auteur)

Carte postale, « Dahomey. Un catéchisme d'adultes à Cotonou »

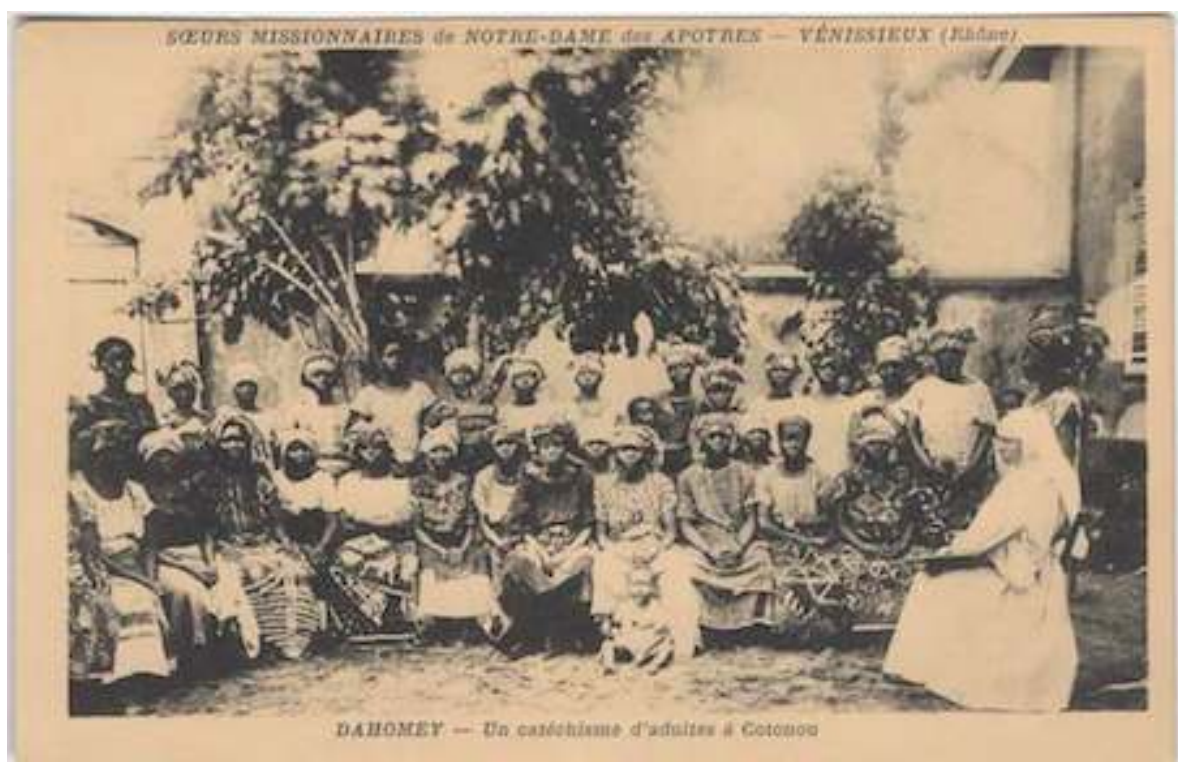

Sans date, Sœurs Missionnaires de Notre-Dame des Apôtres (collection de l'auteur) 
Image 9. Carte postale, «Dahomey. Catéchisme à domicile »

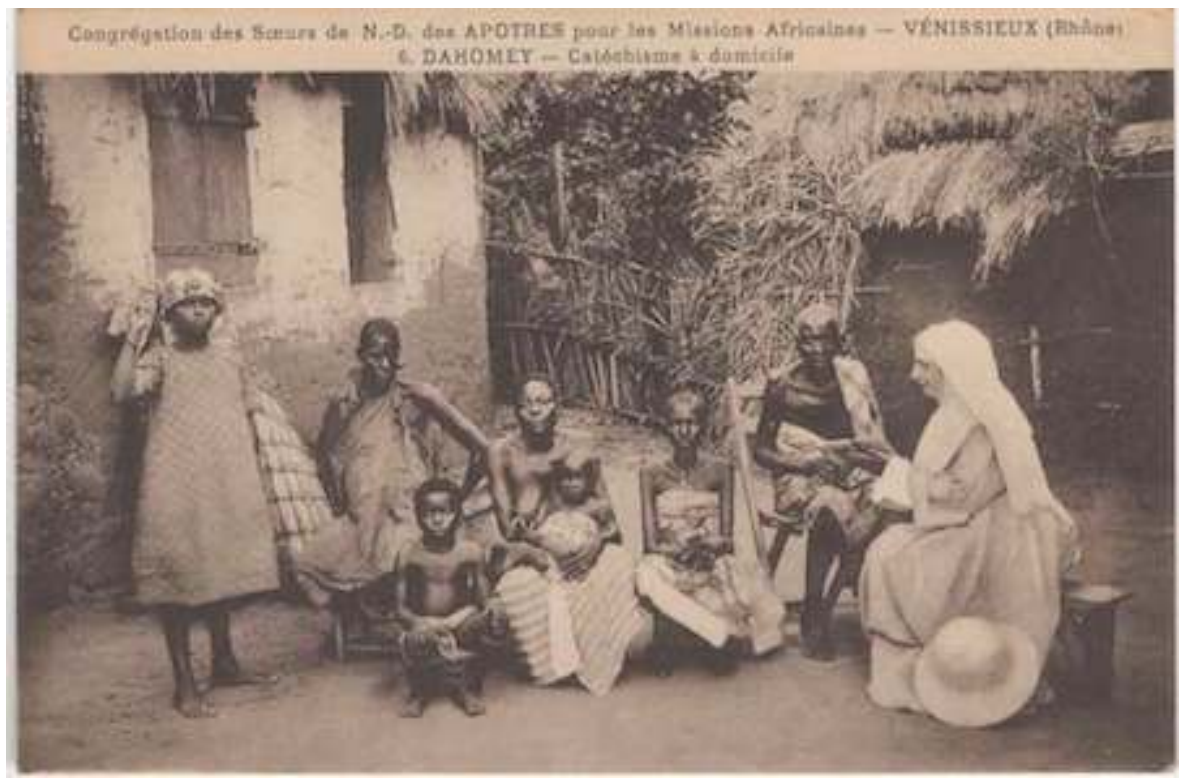

Sans date, Sœurs Missionnaires de Notre-Dame des Apôtres

(collection de l'auteur)

Si les religieuses sont photographiées en position assise, au même niveau que les catéchumènes, leur couleur de peau, leurs vêtements blancs et leur casque colonial (attribut caractéristique porté ou posé sur le sol à leur côté) font contraste. Ces leçons de catéchisme témoignent surtout du rôle central du livre et des images dans la prédication ${ }^{17}$. Sur les cartes postales missionnaires, les religieuses figurent dans des positions de lectrices ou de commentatrices d'images, gravure déposée sur un chevalet improvisé ou livre ouvert et tourné vers les auditeurs et auditrices (qui regardent cependant davantage le photographe que l'image qui leur est présentée). De nombreuses cartes postales proposent ainsi une image dans l'image, de sorte que le récepteur de la carte postale peut lui-même regarder l'image de piété montrée au groupe de catéchumènes. La leçon de catéchisme entretient donc des relations étroites avec la leçon de choses, la piété avec la pédagogie, comme en témoigne l'usage que font les religieuses des supports visuels dans l'enseignement scolaire. 
Image 10. Carte postale, «Quittah (Côte d'Or). Classe enfantine »

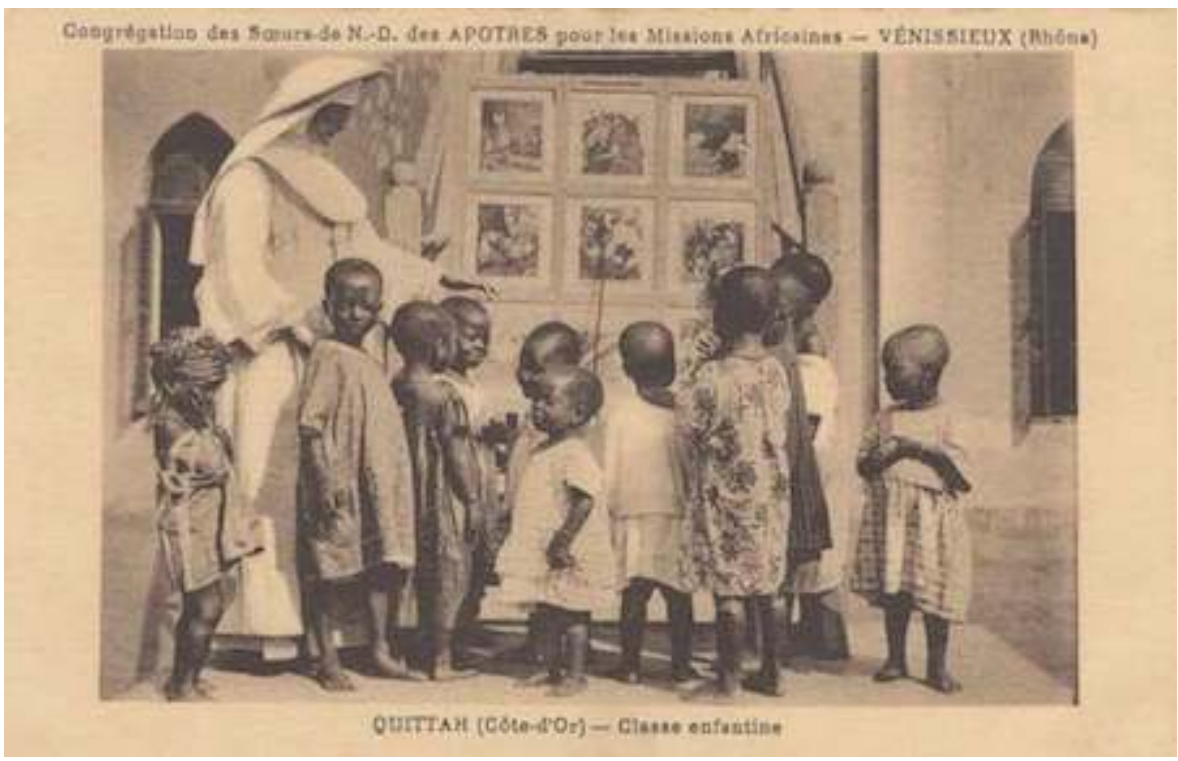

A circulé en 1928, Sœurs Missionnaires de Notre-Dame des Apôtres

(collection de l'auteur)

Les cartes postales révèlent ainsi l'introduction de nouveaux rapports aux images en Afrique de l'Ouest. La catéchèse en images (le recours aux images de piété et aux catéchismes en images) rejoint également la propagande par l'image (la production et la diffusion de cartes postales mettant en scène un tel recours à la figuration) ${ }^{18}$.

Parmi les représentations des leçons de catéchisme, celles faites aux lépreux occupent une place spécifique. La figure du lépreux signale à la fois l'existence d'un paradigme médical dans l'activité missionnaire (Bouron, 2012) et la lutte contre la lèpre comme outil de contrôle des territoires de l'empire colonial (Silla, 1988). La proximité visuelle des religieuses avec les malades et leur place au milieu du groupe valent démonstration de leur dévouement, la maladie renforçant l'impression d'altérité, le mixte de fascination et de répulsion que le corps malade est susceptible de produire chez les récepteurs de telles cartes postales ${ }^{19}$. 
Image 11. Carte postale, « Cap Coast (Côte d'Or). Catéchisme aux lépreux »

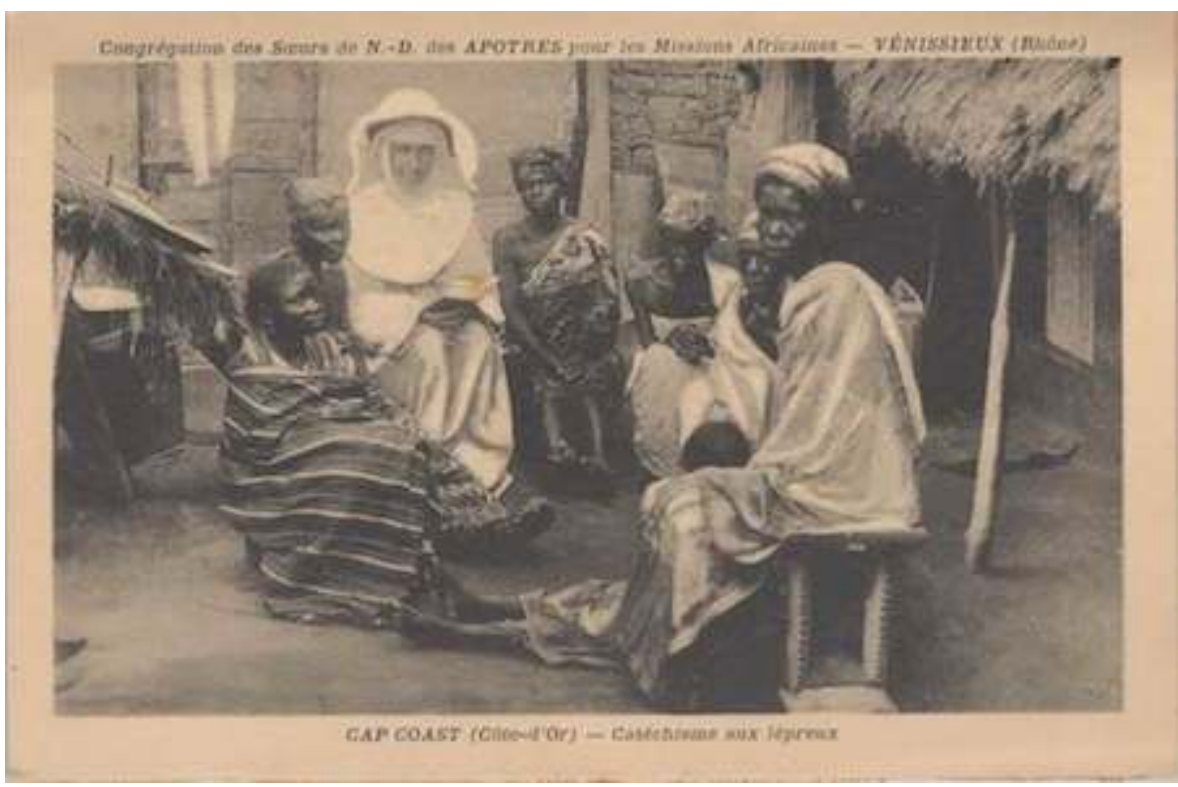

Sans date, Sœurs Missionnaires de Notre-Dame des Apôtres

(collection de l'auteur)

Image 12. Carte postale, «Catéchisme aux lépreux à la Côte d'Or »

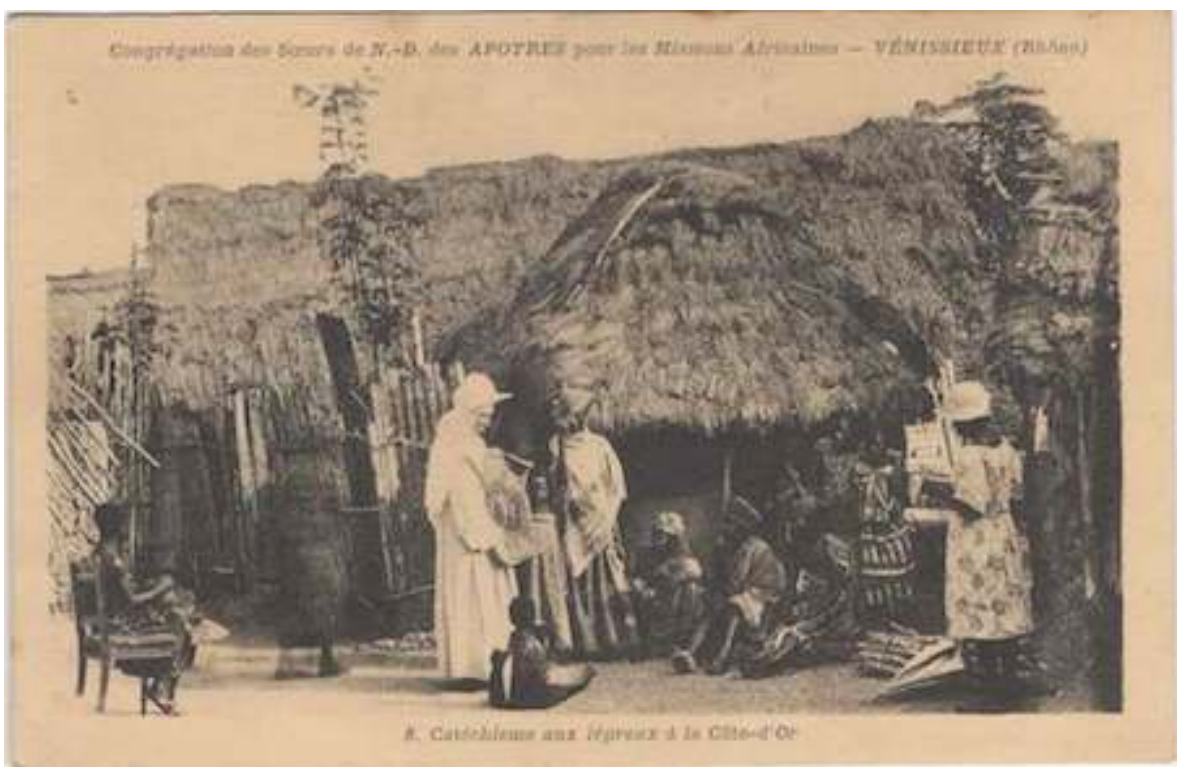

Sans date, Sœurs Missionnaires de Notre-Dame des Apôtres

(collection de l'auteur)

La leçon de catéchisme aux lépreux illustre, en outre, l'argument récurrent dans la littérature missionnaire de l'époque selon lequel les soins du corps seraient en même temps des moyens d'action spirituels - il s'agit de s'occuper «à la fois de leurs corps et de leurs âmes " (Gorjus, 1915, 252). Les représentations de la leçon de catéchisme aux lépreux peuvent ainsi être mises en lien avec les cartes postales dédiées aux activités d'infirmières des religieuses, parfois photographiées en train de soigner des lépreux. 
Image 13. Carte postale, « Sœurs soignant les lépreux »

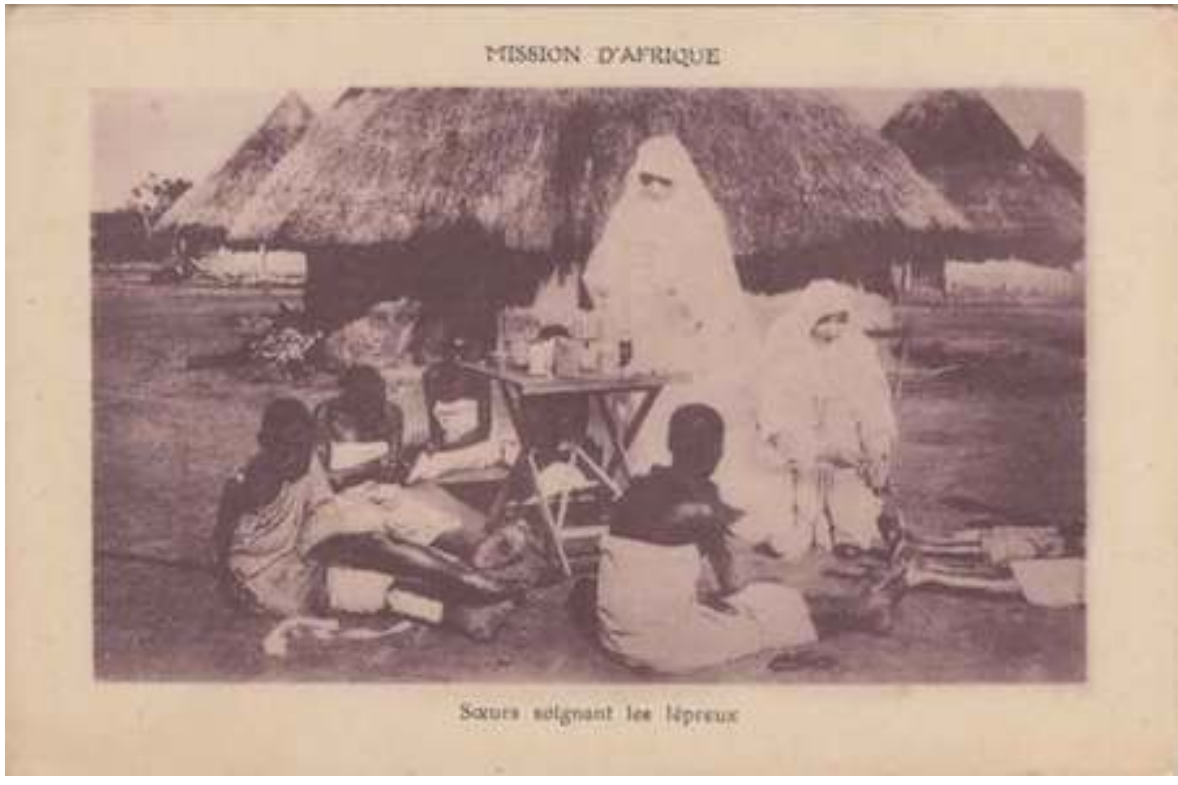

Sans date, Sœurs Missionnaires de Notre-Dame d'Afrique

(collection de l'auteur)

Ce passage par les corps, ceux des malades et des religieuses, soulève néanmoins un problème théologique concernant la distinction entre le corps et l'âme. De même, l'image, qu'il s'agisse d'images de piété ou de cartes postales missionnaires, est précisément le lieu où le spirituel peut faire signe, s'incarner. Dans cette logique, ces cartes postales sont sans doute moins inspirées par l'imagerie de la médecine coloniale que par les représentations d'origine médiévale de Saint-François d'Assise soignant les lépreux ${ }^{20}$. La prégnance du discours franciscain dans l'entreprise missionnaire explique que l'inscription corporelle des religieuses aux côtés des malades de la lèpre soit utilisée dans l'imagerie propagandiste.

Les tournées apostoliques et les leçons de catéchisme n'ont pas seulement pour fonction d'étendre l'influence des missionnaires dans les villages éloignés des postes et de favoriser la prédication directe et «à domicile» (pour reprendre l'expression utilisée dans les légendes de plusieurs cartes postales). La présence des sœurs se retrouve en soi dotée d'une vertu apologétique :

«Par leur seule présence, en de telles sociétés, les femmes missionnaires sont, pour les indigènes, une troublante apologétique. Ils les voient à l'œuvre, instruites, laborieuses, dévouées, saintes... et libres. La femme, à son tour, les envie et les admire, tout en prenant conscience de son abaissement. C'est une force de grâce surnaturelle et de transformation sociale qui se manifeste ainsi dans un monde où la femme n'est encore guère plus qu'un instrument de plaisir ou une main-d'œuvre peu coûteuse » (Beaupin, 1929, 35)

L'activité des femmes missionnaires est pensée sur le mode de l'infusion lente, insidieuse, d'un ensemble de valeurs (parmi lesquels le travail occupe une place essentielle). L'objectif est de fournir aux populations visitées, et prioritairement aux femmes, un modèle de féminité répondant aux normes occidentales et chrétiennes. La figuration de ces tournées et de ces leçons, dont le catéchisme aux lépreux fournit l'exemple le plus fort, participe de la même intentionnalité - comme si la diffusion des cartes postales reproduisait la tournée des religieuses et la leçon à domicile. En mettant 
en avant le dévouement des sœurs missionnaires, les maisons éditrices des cartes postales encourage l'admiration des catholiques français et sollicite leur bienfaisance.

\section{Ménagères en formation}

30 L'exemplarité des sœurs missionnaires est également considérée comme un atout pour l'« apostolat indirect ", à commencer par l'enseignement ménager mis en place dans les écoles et les internats :

«Les Sœurs [...] cherchèrent à créer un genre d'institution qui ne serait ni absolument une école, ni absolument un ouvroir ni absolument un patronage, et où les jeunes négresses s'exerceraient à la tenue d'un ménage et aux tâches diverses que leur imposeraient un jour la vie conjugale et la besogne de mères de famille. C'était là du neuf pour elles, du très neuf, et celles qui profitèrent de la formation donnée par les Sœurs rentraient chez elles avec une habileté manuelle qui leur donnait une supériorité sur les négresses élevées à la mode indigène, et avec certaines impressions, certaines notions, certains goûts, certains débuts d'habitude, qui opéraient en leurs âmes à la façon d'un ferment, et qui devenaient le point de départ de certaines évolutions intellectuelles et morales. » (Goyau, 1933, 188)

31 L'objectif n'était pas seulement de faire des jeunes filles dont elles avaient la charge des mères affectives, des épouses exemplaires et de bonnes chrétiennes. Elles devaient également les former à devenir de parfaites "maîtresses de maison ", à une époque précisément où l'enseignement ménager connaissait, en France, un véritable essor. Les missionnaires s'inscrivent alors dans un projet impérial de transposition du modèle bourgeois de rationalisation du travail domestique féminin élaboré dans les sociétés occidentales (Martin, 1980 et 1987 ; Piette et Gubin, 2001). L'enseignement ménager était ainsi présenté comme un moyen de porter une «attention de plus en plus profonde [...] à la vie intime de l'indigène » et d' " améliorer dans une certaine mesure la condition des femmes »(Randau, 1940, 99) ${ }^{21}$. Il reposait principalement sur une pédagogie par l'exemple, dans laquelle l'imitation jouait un rôle central et justifiait que les jeunes filles accompagnent au quotidien les religieuses dans leurs différentes tâches :

«Un an, peut-être même davantage, ne sera pas de trop pour se familiariser avec la tenue correcte d'un ménage, les divers ouvrages domestiques et, si l'occasion se présente, soins d'hygiène des petits enfants que déjà la jeune fille entrevoit à son foyer dans un avenir assez proche... Tantôt elle aide la Supérieure aux travaux d'intérieur, tantôt elle l'accompagne auprès de quelque malade, prenant ainsi contact avec la souffrance dont on lui fait découvrir la valeur et le mérite. Tout le long du jour, mille incidents se présentent dont la Religieuse profite, aidée en cela par l'intérêt très vif de la jeune fille, pour éveiller sa personnalité, créer en elle le sens de ses responsabilités, lui apprendre par l'exemple ce qu'est le dévouement. Vivre ainsi au contact immédiat des Sœurs, dans un milieu de fidélité au devoir, de respect et d'égards réciproques, est pour la jeune fille Noire douée de perspicacité et d'esprit d'imitation, d'une réelle et profonde efficacité. » (Strebler, s. d., 86)

Ainsi, si l'éducation féminine est envisagée comme un moyen d'émanciper les femmes africaines du travail agricole que leur imposent les hommes dans ce qui est décrit comme du «sevrage » ou comme une forme d'esclavage, c'est paradoxalement pour leur attribuer d'autres tâches: "la femme, délivrée d'une multitude de besognes d'ouvrière agricole, pourra se livrer à la fois avec une moindre fatigue et un plus grand rendement aux besognes ménagères qui sont ses besognes propres » (Wilbois, 1938, 120). L'enseignement ménager est le lieu d'un transfert de normes et de jugements 
moraux qui définissent ce que doit être, aux yeux des missionnaires, un travail convenable pour les femmes - qui leur assignent donc une place dans des rapports sociaux de sexe.

L'enseignement ménager (et l'école ménagère en particulier) est l'un des espaces représentés de manière privilégiée dans les cartes postales missionnaires. Les sœurs, présentes en arrière-plan ou sur le côté des groupes de jeunes filles, encadrent leur travail de manière discrète. Sur une carte postale consacrée à l'école ménagère de Quittah, en Basse-Volta, la seule religieuse présente s'efface presque sur la gauche d'un groupe de femmes qui font la lessive ou étendent le linge.

Image 14. Carte postale, "L'école ménagère de Quittah (Basse-Volta) »

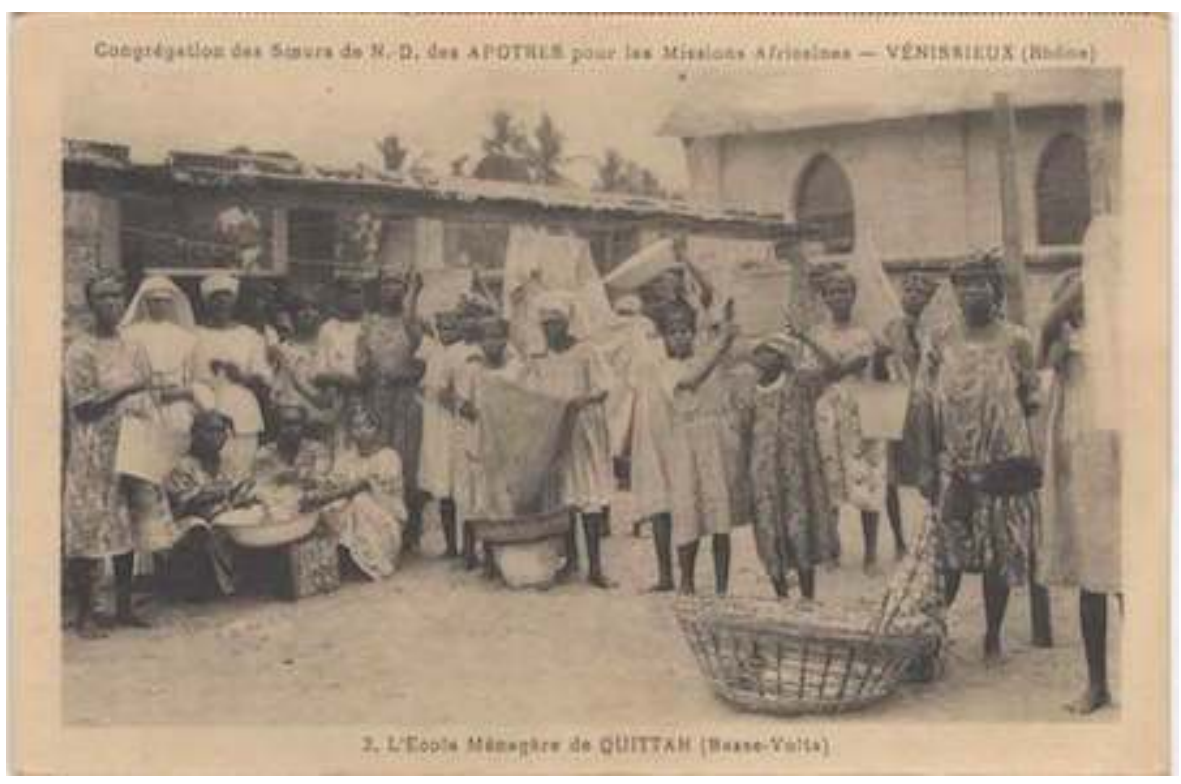

A circulé en 1943, Sœurs Missionnaires de Notre-Dame des Apôtres

(collection de l'auteur)

Ce travail de blanchisserie est rarement représenté. Il évoque une forme de division sexuelle dans l'organisation de la vie quotidienne des missions, les religieuses ayant pour tâche d'assurer la cuisine, la lessive et les travaux de couture des pères. Les femmes missionnaires étaient, en effet, considérées comme les «auxiliaires» «humbles», "zélées» ou "dévouées» (pour reprendre les termes habituellement utilisés à l'époque) - des hommes missionnaires. L'entreprise missionnaire était ainsi organisée comme un «système de la sujétion féminine par rapport à l'élément masculin » (Pirotte, 2005, 21) 22. De ce point de vue, le statut des religieuses était proche de celui des « indigènes » convertis et recrutés comme moniteurs.

Dans ce contexte, former sur place des jeunes filles à ces diverses tâches ménagères n'avait pas seulement pour objectif d'en faire " des maîtresses de maison accomplies " ou « de bonnes mères de famille capables d'élever leurs enfants et d'en faire des hommes $»^{23}$. Cela pouvait également permettre aux religieuses de leur déléguer un certain nombre de tâches dépréciées et de les utiliser comme domestiques, au service des missionnaires. L'enseignement ménager dépassait ainsi le cadre scolaire de l'école ménagère et s'inscrivait dans celui de la division sexuelle du travail missionnaire et du développement d'une domesticité coloniale. Dans une certaine mesure, il fournissait 
donc aux religieuses l'occasion de passer d'une position subalterne à une position dominante (Langewiesche, 2012 ; Bouron, 2014). La préparation des hosties donnait, par exemple, lieu à une répartition du travail plaçant la religieuse en bout de chaîne, juste avant leur consécration.

Image 15. Carte postale, « La préparation des hosties à Agoué (Dahomey) »

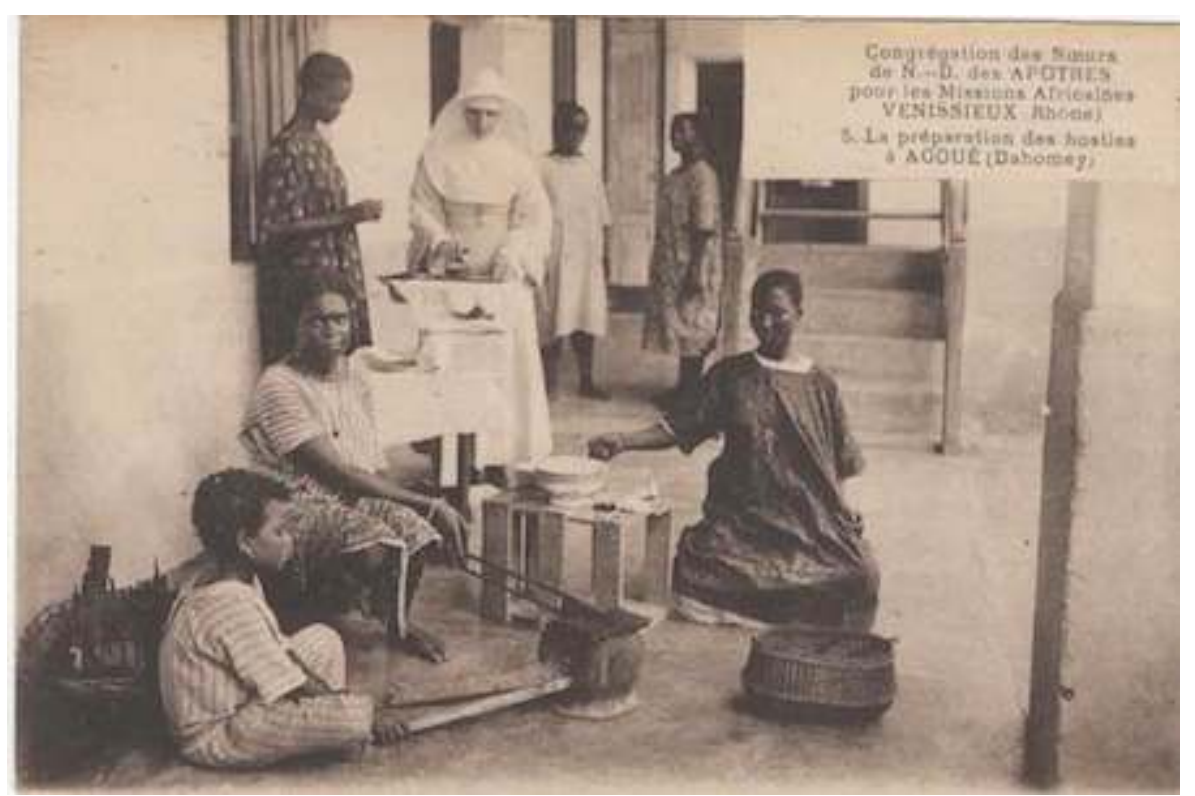

A circulé en 1931, Sœurs Missionnaires de Notre-Dame des Apôtres

Au verso, on lit : "Chère Madame. Au palais des Missions nous avons pensé à toutes deux. C'est magnifique. » Cette carte a donc sans doute été achetée à l'occasion d'une visite à l'Exposition Coloniale, peut-être à Justine.

(collection de l'auteur)

La cuisine mise en image ici n'est pas celle des repas des missionnaires, mais celle, sacrée, qui produit le corps du Christ tout en le diffractant.

La mise en scène de la lessive ou de la cuisine reste néanmoins exceptionnelle, au regard des nombreuses cartes postales consacrées à la couture et autres travaux d'aiguille. Une telle imagerie associant féminité et couture s'est largement développée au cours du XIXe siècle, quand « la couture était beaucoup plus associée au sexe qu'au milieu social, et procurait ainsi une image du travail des femmes qui évitait toute controverse sur les différences sociales et économiques comme sur le travail industriel, privilégiant un modèle consensuel » (Higonnet, 2002, 362). La production d'un tel cliché est d'autant plus pertinente aux yeux des missionnaires qu'il s'inscrit dans un double processus de féminisation de la couture et d'émergence d'une «spiritualité de l'aiguille ", qui se développe en France à partir du XVIIIe siècle (Pellegrin, 1999) - la couture est d'ailleurs de longue date associée à la figure de la Vierge Marie (AlbertLlorca, 1995).

Deux siècles plus tard, les colonies ouest africaines sont à leur tour l'espace où les travaux d'aiguille, sous l'impulsion des missionnaires, deviennent féminins. Ils sont vus comme un moyen de discipliner les corps des jeunes filles, de leur donner une «leçon de maintien » : comme dans les campagnes françaises, on considère en effet qu' " elles portent en elles des pouvoirs qu'il convient de maitriser, ne serait-ce que pour mieux en garantir l'usage » (Verdier, 1979, 256). Dans les cartes postales missionnaires, cette 
discipline des corps se traduit par l'alignement des jeunes filles prenant la pose et faisant mine d'être concentrées sur leur ouvrage.

Image 16. Carte postale, « Togo. L'école ménagère de Lomé »

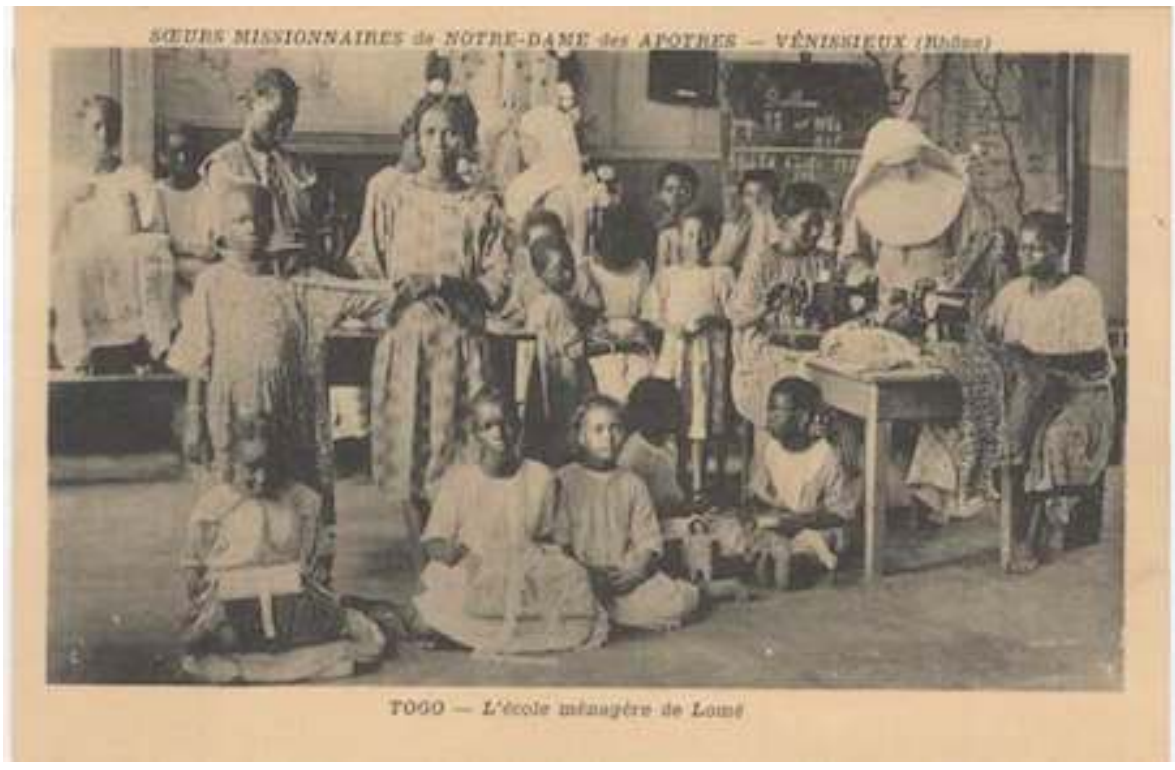

Sans date, Sœurs Missionnaires de Notre-Dame des Apôtres

(collection de l'auteur)

Sur l'une des cartes postales consacrées à l'école ménagère de Lomé, tandis que plusieurs d'entre elles s'exercent à la dentelle ou s'entraînent à la machine à coudre sous la houlette d'une religieuse, une fille plus âgée mesure la manche de l'une de ses petites consœurs à l'aide d'un mètre à couture. Toutes deux cependant regardent l'objectif, ce qui rend leur pose d'autant plus curieuse. Le corps mesuré et photographié n'est pas ici celui des photographies anthropométriques, mais celui de la féminité métrée et normée ${ }^{24}$.

Les travaux d'aiguille sont également donnés à voir dans deux cartes postales éditées par les Sœurs Missionnaires de Notre-Dame des Apôtres. La première, intitulée «Le travail manuel », montre une trentaine de jeunes filles posant en train de faire de la broderie et de la dentelle. 
Image 17. Carte postale, « Dahomey. Agoué. Le travail manuel »

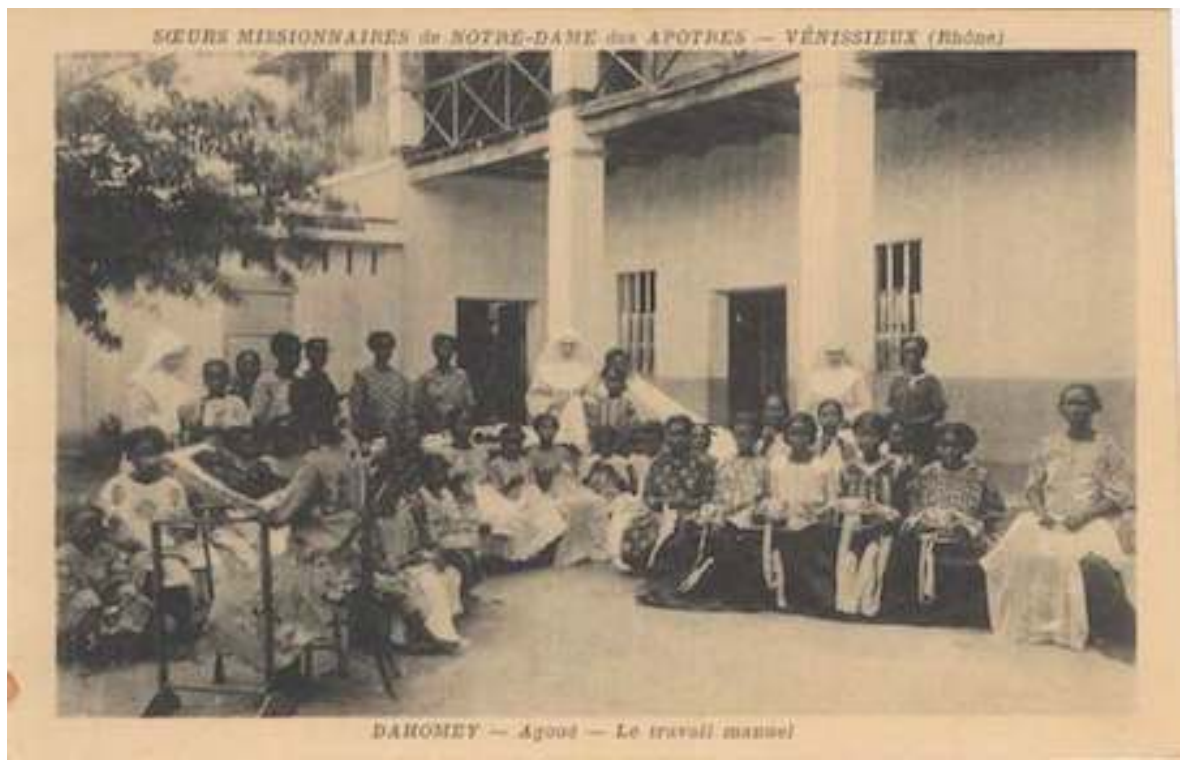

Sans date, Sœurs Missionnaires de Notre-Dame des Apôtres

(collection de l'auteur)

41 Trois religieuses sont derrière elles, dont deux se confondent presque avec les deux piliers du bâtiment en arrière-plan - sur le plan iconologique donc, elles sont les piliers $\mathrm{du}$ groupe. Sur l'autre, quatre jeunes filles font de la dentelle au fuseau (parmi lesquelles on reconnaît certaines déjà présentes sur l'image précédente). La légende de la carte, «Jeunes filles noires faisant la dentelle au fuseau», ne mentionne pas la religieuse qui, à gauche de l'image, rassemble les rubans de dentelles produits par les quatre apprenties en une seule large bande.

Image 18. Carte postale, «Agoué (Dahomey). Jeunes filles noires faisant la dentelle au fuseau »

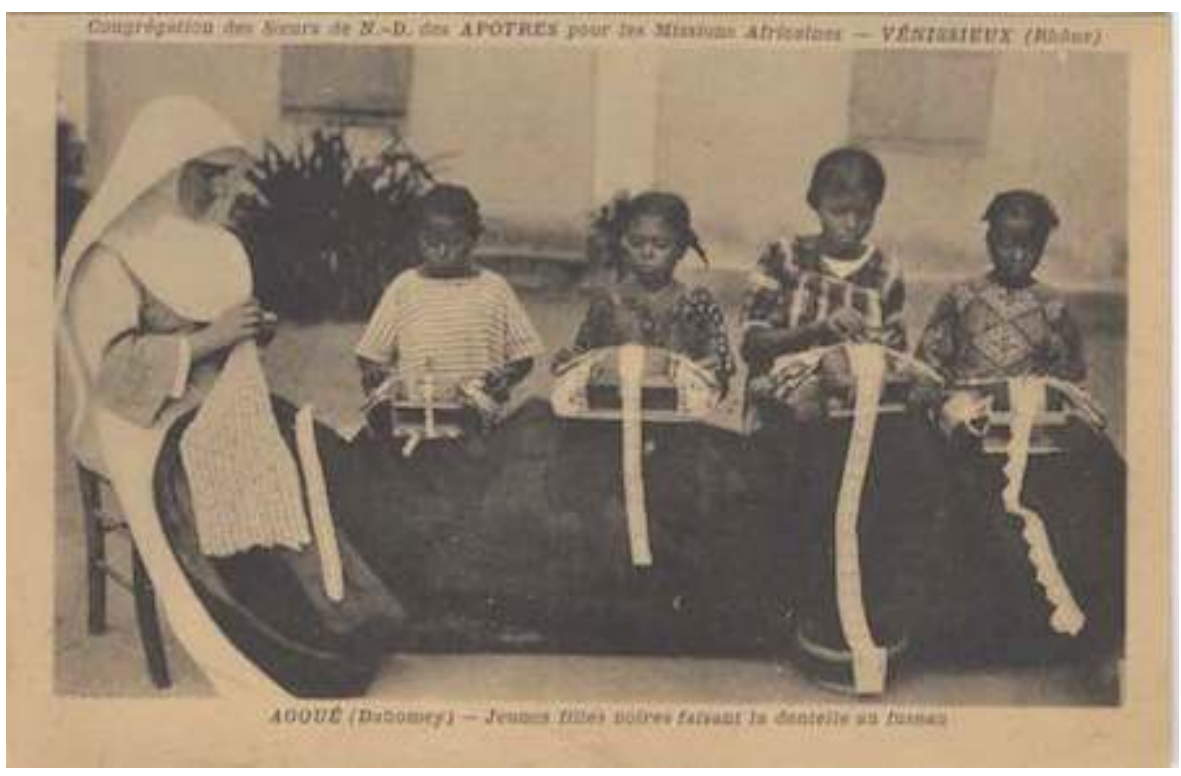

Sans date, Sœurs Missionnaires de Notre-Dame des Apôtres

(collection de l'auteur) 
Comme pour la fabrication des hosties, la sœur assume la phase finale de la production. Mais les travaux d'aiguille trouvent ici une autre signification, spécifique : à partir du travail de chacune des jeunes filles, les missionnaires font œuvre collective.

\section{Machines à coudre et métiers à tisser}

43 Les travaux d'aiguille sont également à l'honneur des nombreuses unités de production textile que sont les ouvroirs créés au sein des missions. La distinction entre écoles ménagères et ouvroirs, les premières dédiées à l'apprentissage et les seconds à la production, est d'ailleurs toute relative. Dans l'une de ses conférences consacrées aux unes, Sœur Marie-André du Sacré-Cœur vantait ainsi les mérites des autres :

«Les enfants y acquièrent la connaissance d'un métier, les jeunes filles y trouvent un salaire avantageux et une ambiance saine et familiale. Le travail est proportionné aux forces de la jeune fille et aux ressources du pays; il est aussi presque toujours artistique, ce qui est à considérer pour l'avantage et le développement intellectuel de l'ouvrière. ${ }^{25}$

Quelques années plus tard, une religieuse anonyme insistait sur l'ouvroir comme espace privilégié de l'«apostolat indirect» où les «jeunes filles se préparent par le travail et la pratique d'une vie sérieuse et disciplinée, à fonder des foyers chrétiens et à devenir de bonnes épouses et mères de famille " (Anonyme $1935: 124-125$, note 1, et 132-133). Les religieuses mettent également en avant les rémunérations des ouvrières, qui leur permettent de se constituer une dot ou leur assurent un petit revenu jugé émancipateur - en réalité, les jeunes femmes sont souvent contraintes de fréquenter l'ouvroir (Diarra, 2009, 132-133) et les bénéfices sont trop maigres pour assurer la pérennité du système (Bobin, 2003), d'ailleurs pensé à l'origine comme un moyen d'assurer le financement de la mission.

Les ouvroirs occupent une position privilégiée dans la propagande missionnaire. Sur place, les administrateurs coloniaux leur rendent de nombreuses visites et font partie des rares clients locaux, notamment grâce aux commandes qu'ils passent auprès des religieuses. Les produits sont, cependant, majoritairement exportés pour être vendus par les comités de dames dans le cadre des ventes de charité organisées en métropole au profit des œuvres missionnaires. Ils sont valorisés sur les stands des missions dans différentes foires ou expositions, à l'occasion desquelles ils reçoivent parfois des prix. En 1922, l'ouvroir de Ouagadougou reçoit le grand prix de l'exposition coloniale de Marseille (de Benoist, 1987, 332-333). Les tapis de Ségou et de Ouagadougou obtiennent la médaille d'or de l'exposition des Arts Décoratifs de 1925, à Paris (Diarra, 2009, 132, note 15). La même année, de nombreux travaux d'aiguille sont également exposés lors de la grande exposition missionnaire du Vatican. Un tel succès s'explique indissociablement par la qualité esthétique des produits et par la valeur testimoniale qui leur est attribuée : ils objectifient la mise au travail des femmes ouest africaines et les prétendus succès civilisateurs de l'entreprise missionnaire.

Les ouvroirs produisent essentiellement des textiles, mais aussi des vanneries, des colliers ou des objets en perles. Ils se spécialisent souvent dans une technique en particulier: tissage plat et haute-laine, dentelles ou broderies. L'ouvroir de Toma (Soudan français) met par exemple en avant les travaux de dentelles (services à thé et décorations pour meubles) qui donnent lieu à plusieurs cartes postales. Deux d'entre elles présentent la même religieuse, l'air sévère, assise sur un tabouret et supervisant le 
travail de quatre jeunes filles, qui fixent l'objectif dans la première, se penchent sur leur ouvrage dans la seconde.

Image 19. Carte postale, «Soudan français. Un coin de l'ouvroir de Toma »

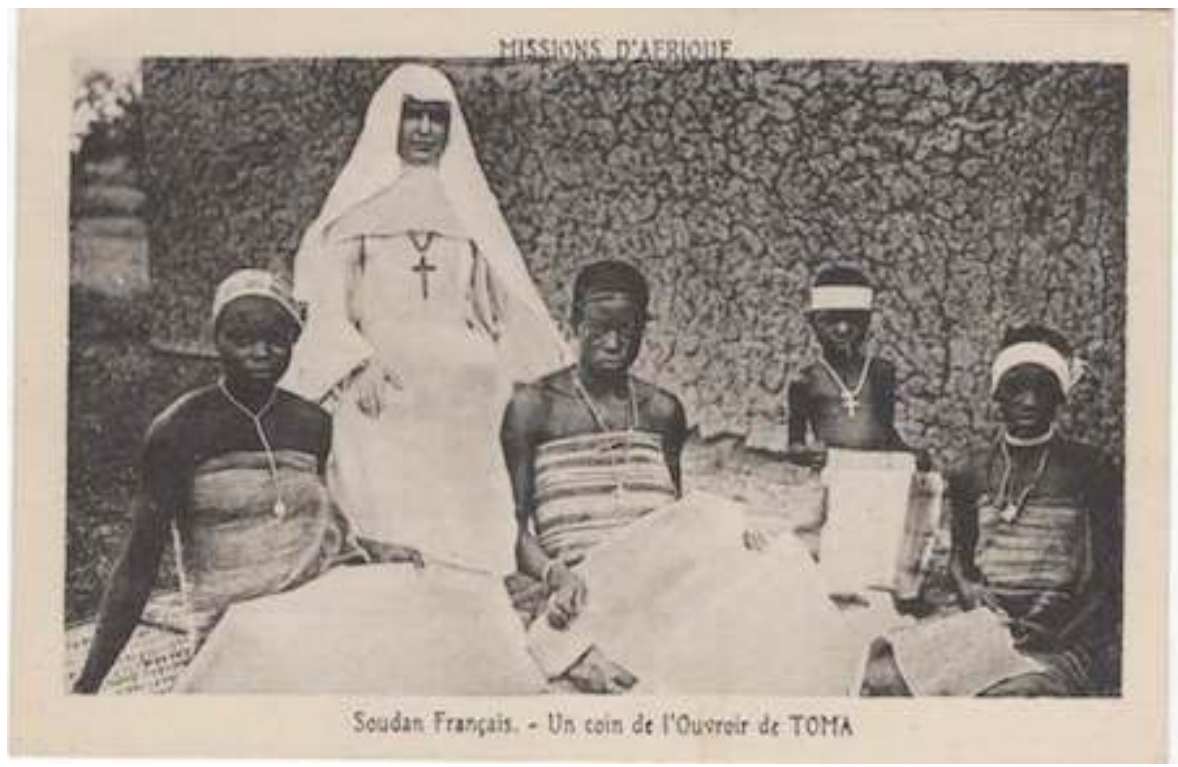

Sans date, Sœurs Missionnaires de Notre-Dame d'Afrique

(collection de l'auteur)

Image 20. Carte postale, « Les dentellières à l'ouvroir des Sœurs »

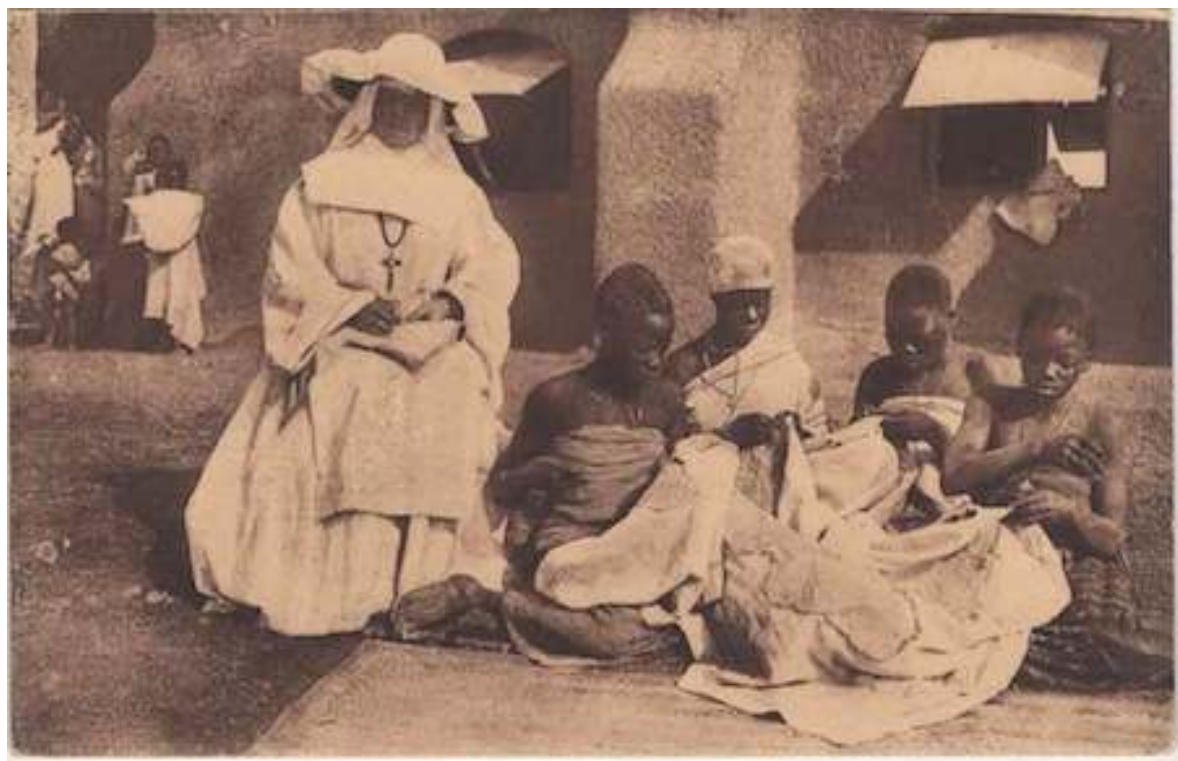

Sans date ni mention d'éditeur (légende au verso)

(collection de l'auteur)

\footnotetext{
travail de dentelles. Une autre présente un groupe plus important d'enfants auquel une religieuse s'est jointe.
}

Les croix portées en pendentifs sont apparentes et la sœur est elle-même en plein 
Image 21. Carte postale, "Tougan. Ouvroir de Toma. Les petites filles apprennent la dentelle sous la direction des Sœurs Blanches»

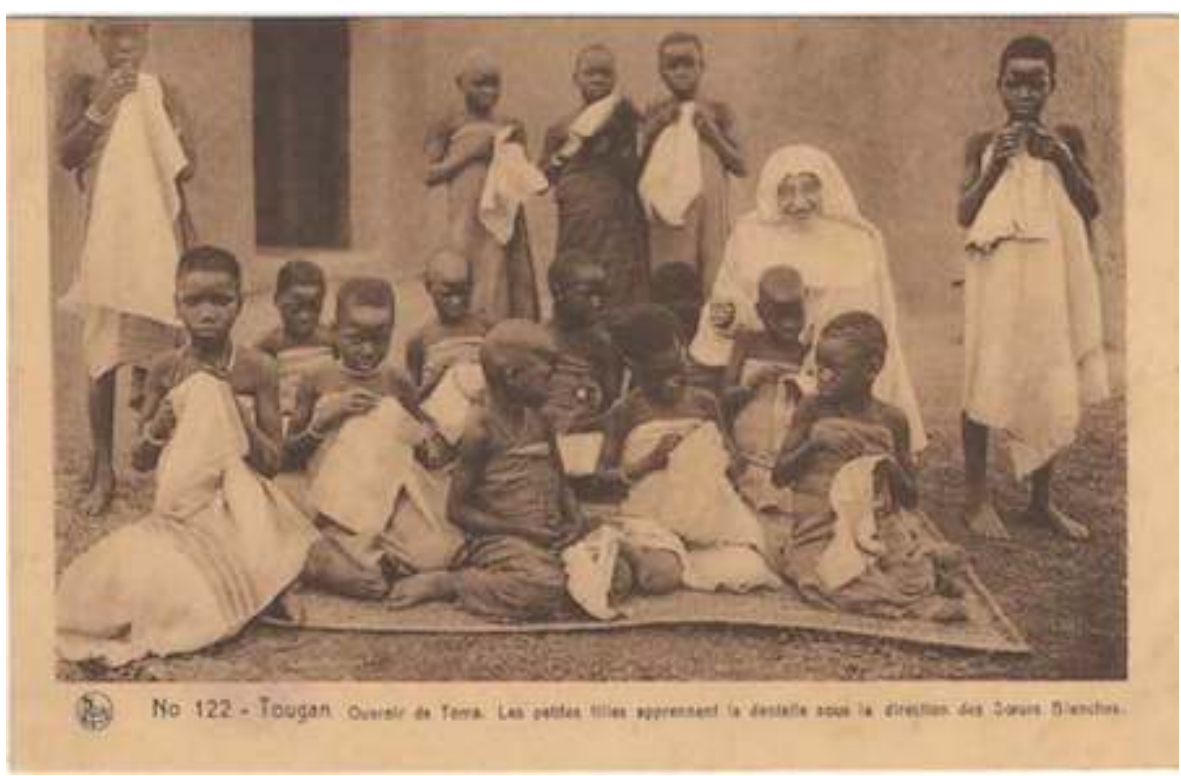

Sans date, édition Volta-Nels

(collection de l'auteur)

La circulation des regards est plus libre ici, mais le photographe a soigneusement organisé le groupe: cinq enfants, debout en arrière-plan, prennent la pose en découpant verticalement l'image. Comme souvent, le blanc des dentelles rappelle celui de la tenue de la religieuse - ici renforcé par le contraste qu'offre l'ouverture sombre dans le mur du fond.

49 La composition de l'image est plus frappante encore dans l'une des cartes postales éditées à l'occasion de l'Exposition coloniale, qui valorise le travail des ouvroirs de Ouagadougou et de Ségou. 
Image 22. Carte postale, « Leçon de dentelle à l'aiguille »

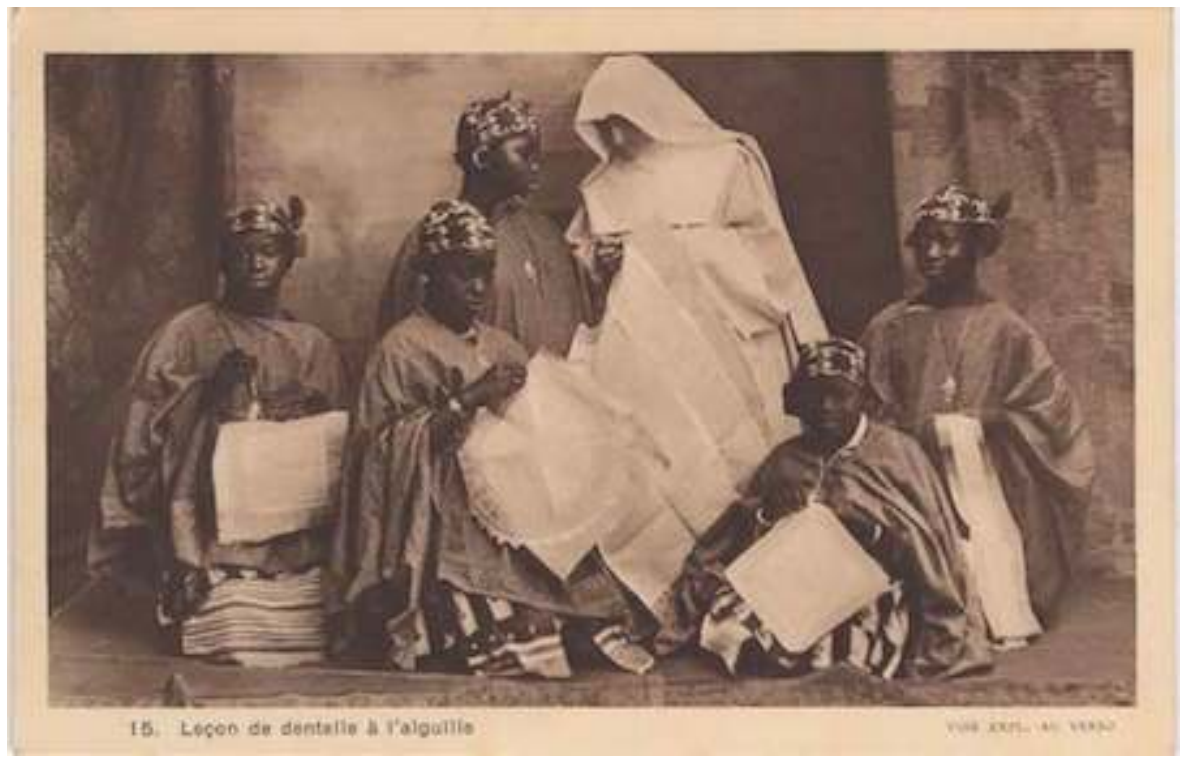

Exposition Coloniale de Paris, 1931, Sœurs Missionnaires de Notre-Dame d'Afrique, St-Charles, édition G.-L. Arlaud, Lyon

(collection de l'auteur)

La sœur, entourée par cinq dentellières (parmi lesquelles, assise à ses pieds, on reconnaît Justine), forme le sommet d'une pyramide et sa tenue immaculée, se détachant d'un fond noir et de la couleur des vêtements et des visages des cinq jeunes filles, se confond dans une succession de plis avec les travaux de dentelles qui lui sont présentés. L'efficacité visuelle de la photographie, sans doute prise dans un studio par un photographe professionnel, repose à la fois sur l'usage des potentialités du noir et blanc et sur le jeu de superposition des surfaces textiles que permet celle de la carte postale. La "leçon de dentelles » met en scène (comme la leçon de catéchisme et la leçon de choses) la présence ambivalente de la religieuse, en même temps qu'une certaine abstraction de son corps à la fois ouvrage et image, produit et représentation.

51 Aux ouvroirs, plus encore que le travail de dentelle, la machine à coudre fonctionne comme un véritable marqueur visuel de civilisation, conjuguant discipline des corps et civilisation des mœurs. 


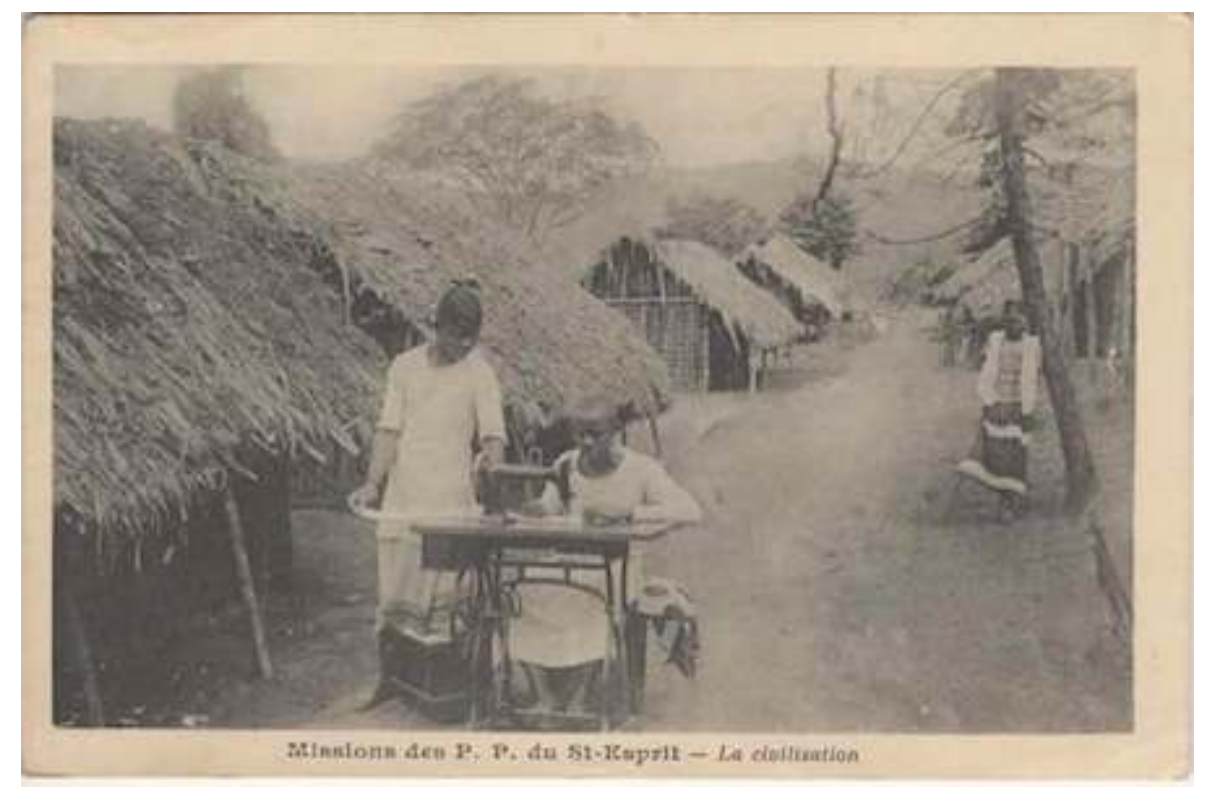

A circulé en 1939, Missions des Pères du Saint-Esprit

La photographie a été prise en Afrique de l'Est. Cette carte est révélatrice de la dimension civilisatrice que les missionnaires attribuent à la machine à coudre

(collection de l'auteur)

Le travail féminin révèle ici la circulation des techniques et permet d'observer les formes d'appropriation d'un ensemble de machines, d'outils, de savoir-faire et de modèles. Le pouvoir de la machine sur le corps est aussi pensé comme un pouvoir sur l'âme. Une religieuse anonyme considérait ainsi l'ouvroir comme « le meilleur moyen d'assainissement moral de la fillette et de la jeune fille " (Anonyme, 1935, 131, note 1). Avec son introduction en Afrique de l'Ouest, principalement par les missionnaires, la couture devient mécaniste et s'ouvre à l'industrialisation, comme en France au cours de la seconde moitié du XIXe siècle, quand la machine à coudre, initialement inventée pour un usage domestique, avait très vite intégré les ateliers de confection et les usines. Elle est donc un parfait trait d'union entre l'activité ménagère et le salariat, entre l'espace domestique et le lieu de travail (Perrot, 1978a et 1983; Coffin, 1994 et 1996; Peyrière, 1996).

Dans les ouvroirs ouest africains, les machines à coudre (souvent offertes par les comités des dames) permettent la professionnalisation des jeunes femmes en même temps qu'elles objectifient les rapports de domination entre cadettes et aînées. Sur l'une des cartes postales consacrée à l'ouvroir de Cotonou, la foule des apprenties et des ouvrières est coupée par l'alignement de trois Singer, sur lesquelles les plus âgées sont penchées: aux plus jeunes (assises au premier plan ou debout en arrière-plan) la dentelle, à leurs aînées les machines. 
Image 24. Carte postale, "Dahomey. L'ouvroir de Cotonou »

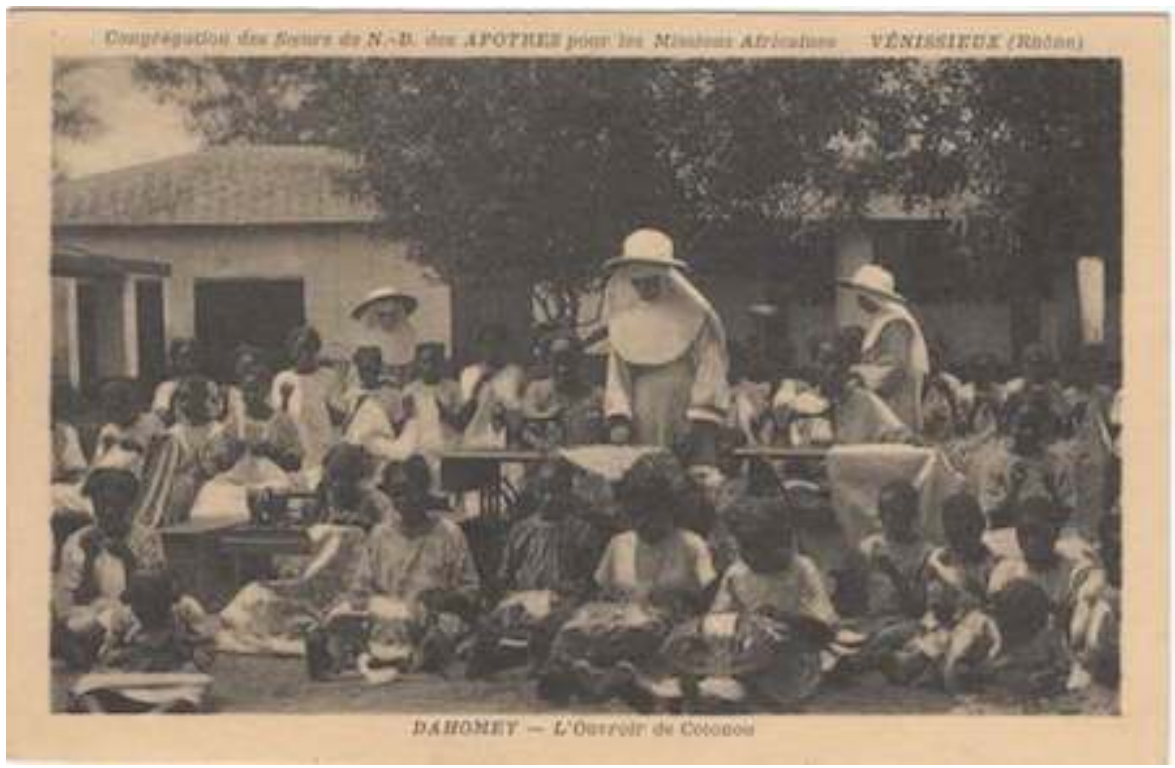

Sans date, Sœurs Missionnaires de Notre-Dame des Apôtres (collection de l'auteur)

La couture est alors l'« un des métiers féminins les plus prestigieux de la colonisation » (Raison-Jourde, 1993, 54) et l'usage des machines conférait à coup sûr un certain prestige. Une carte consacrée à l'ouvroir de Dakar, dirigé par les Sœurs Bleues de Castres, propose un plan plus resserré et une vue d'intérieur d'un alignement de machines sur lesquelles les jeunes ouvrières sont courbées, paraissant attentives.

Image 25. Carte postale, « Dakar. L'ouvroir »

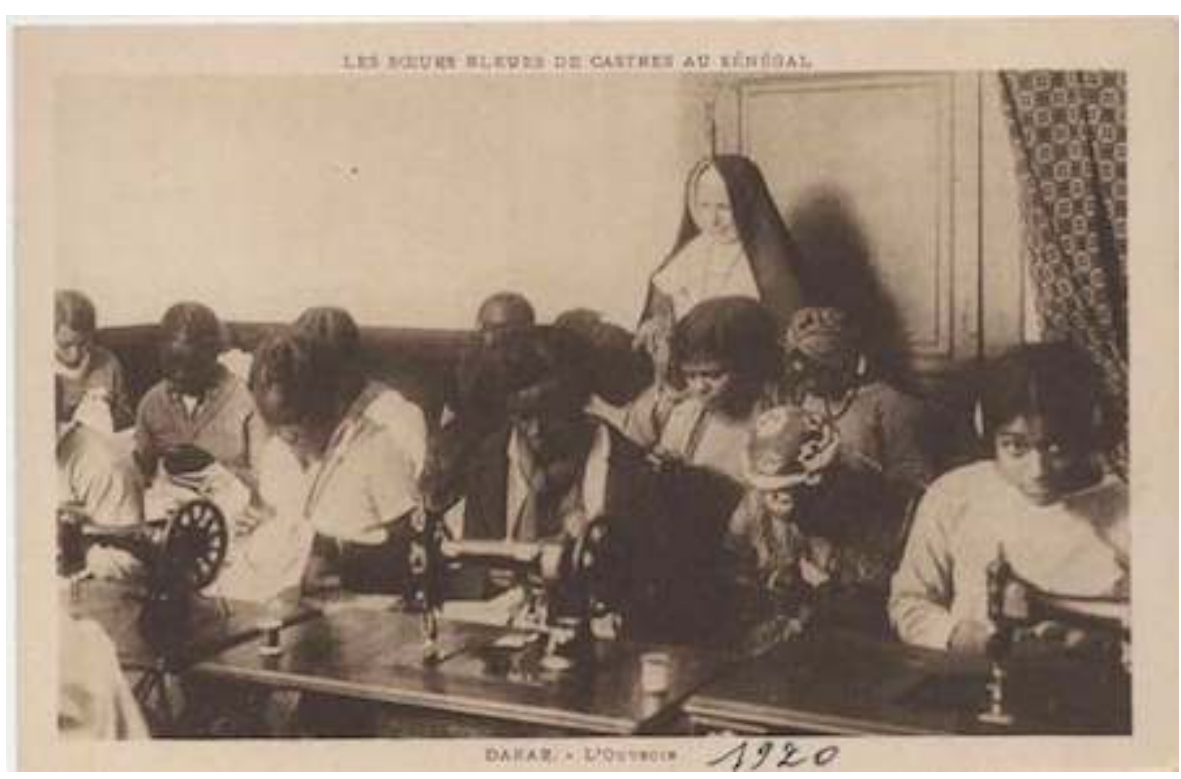

1920 ?, Sans mention d'éditeur

(collection de l'auteur)

Une seule d'entre elles, à droite, regarde le photographe, paraissant établir une relation avec le récepteur de l'image - sur le modèle de celles que les colons pouvaient 
expérimenter sur place, lors de leurs visites des ouvroirs. Si la machine à écrire induit une semblable discipline du corps, elle figure de manière beaucoup plus exceptionnelle sur les cartes postales :

Image 26. Carte postale, «Les Sœurs Bleues de Castres au Sénégal (AOF). Deux jeunes Sénégalaises préparent leur examen commercial»

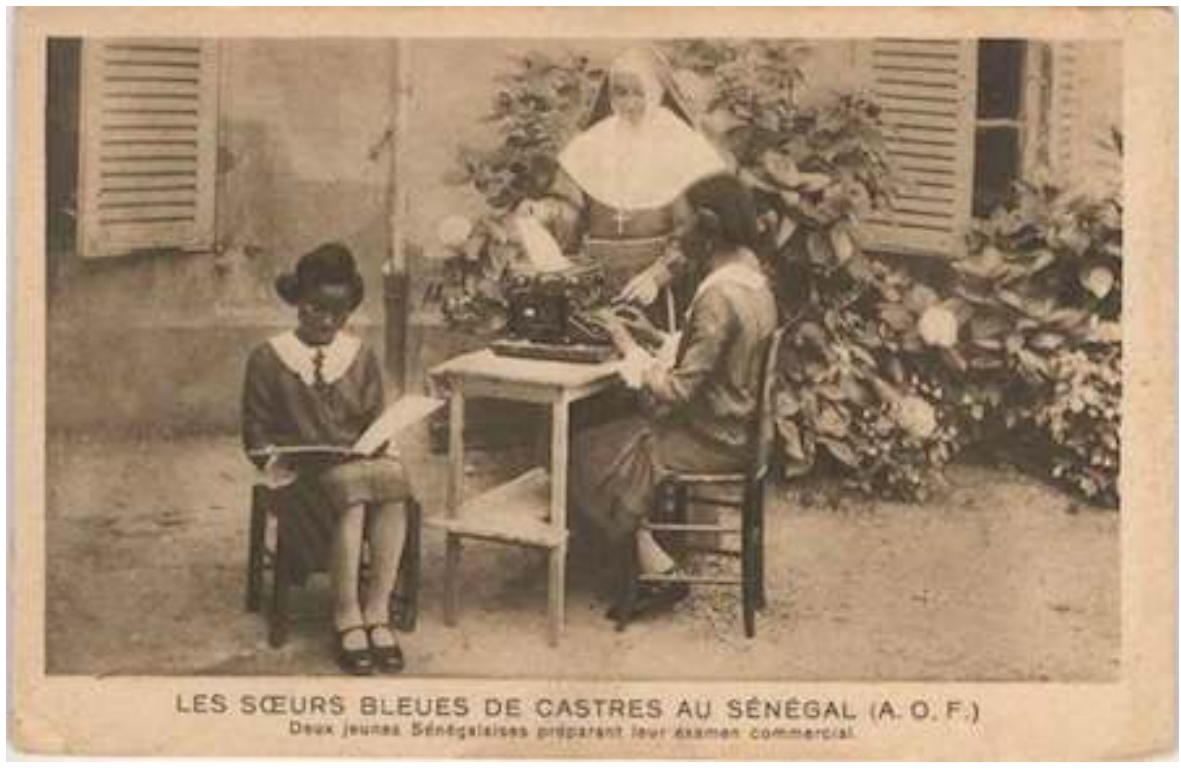

Sans date, A. Joinard éditeur

(collection de l'auteur)

son introduction est moins massive et, surtout, elle ne donne pas à voir la productibilité du travail. À la transmission scolaire de connaissances dactylographiques s'oppose le travail également féminin de la production textile que les missionnaires souhaitent développer à échelle industrielle.

Les ouvroirs qui se spécialisent dans le tissage haute laine fournissent les meilleures images de propagande de cette production en voie d'industrialisation - ils témoignent également de la féminisation d'une activité jusqu'alors largement réservée aux hommes. L'introduction de nouvelles techniques joue là encore un rôle majeur, valorisé par les cartes postales, qu'il s'agisse du remplacement du fuseau par le rouet ou des métiers horizontaux, majoritairement utilisés jusqu'alors, par des métiers de haute lisse. À l'ouvroir de Ouagadougou, les jeunes fileuses travaillent au rouet à pédale. Une carte postale rend compte de leurs gestes et postures contraints par la mécanisation du filage. 
Image 27. Carte postale, «Filage de la laine pour tapis à la Mission de Ouagadougou »

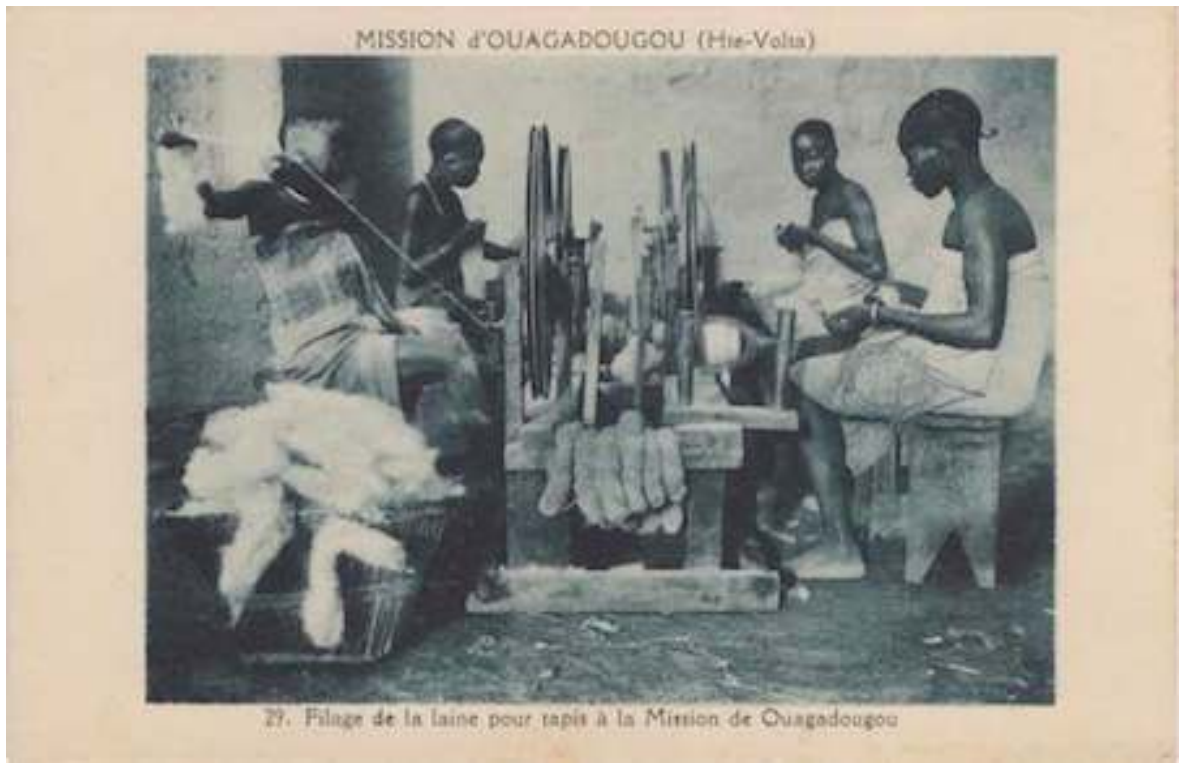

Sans date, Mission de Ouagadougou

(collection de l'auteur)

57 La valorisation de la production textile passe alors par une description des différentes étapes du travail : séchage de la laine, triage, cardage, filage, tissage. Sur certaines cartes, aucune religieuse n'est présente: seule la légende permet la qualification missionnaire. Sur d'autres, une fois de plus, les sœurs sont en arrière-plan, presqu'effacées. Trois cartes consacrées à l'ouvroir de Ségou montrent ainsi les premières étapes de la production des tapis qui font alors la réputation de la mission (illustrations 28, 29 et 30).

Image 28. Carte postale, « Ouvroir de Ségou. Triage de la laine»

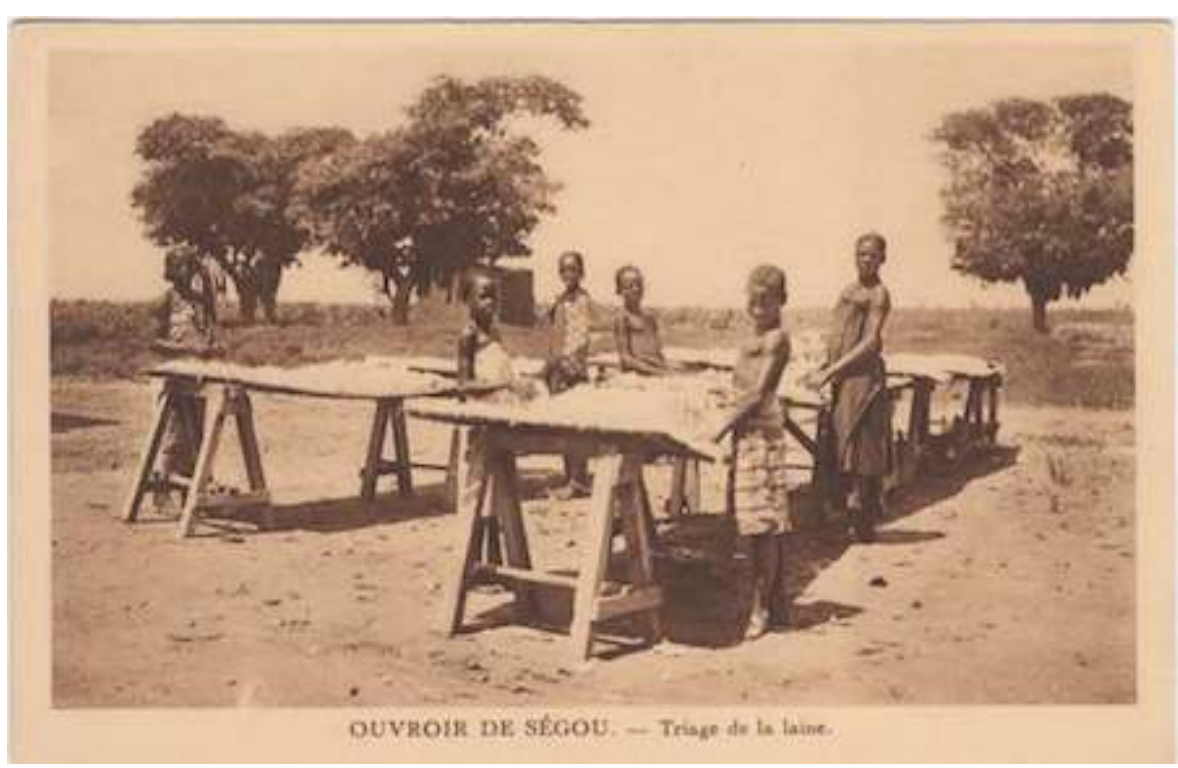

Sans date, Pères Blancs

(collection de l'auteur) 
Image 29. Carte postale, "Ouvroir de Ségou. Fileuses »

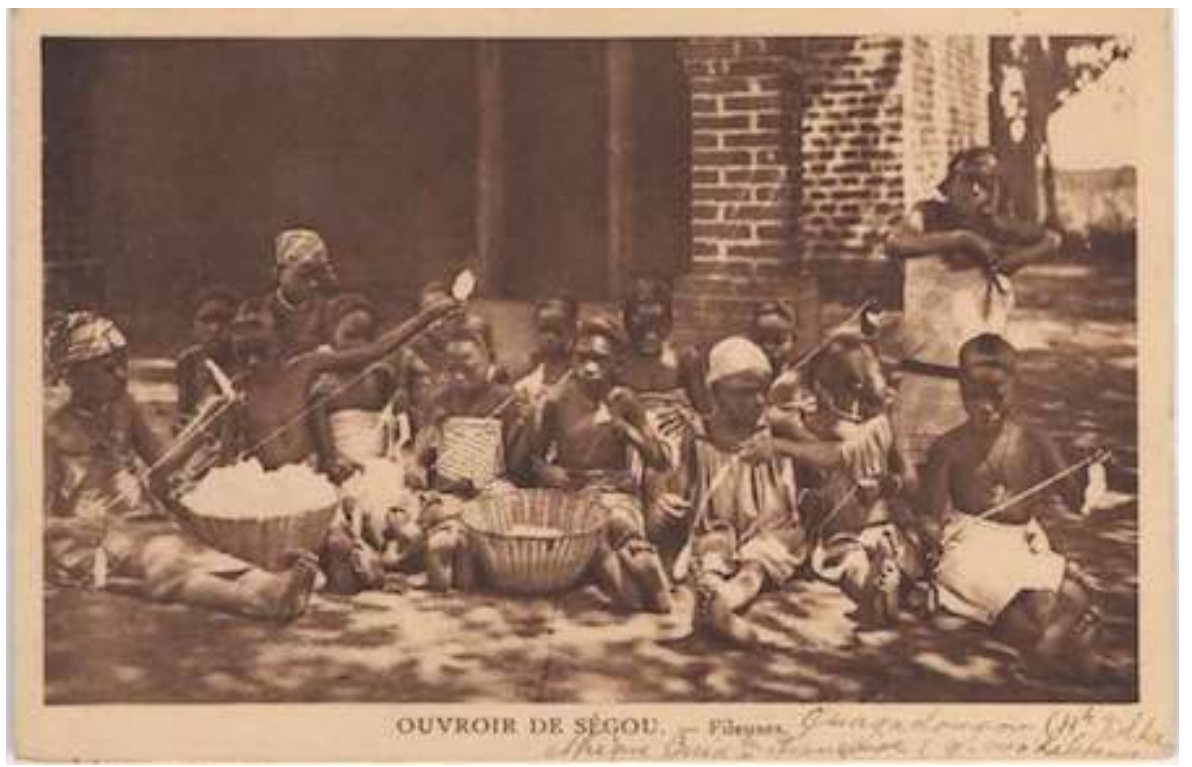

A circulé en 1931, Pères Blancs

Au verso, on lit un extrait du courrier d'une religieuse participant à l'Exposition Coloniale, dans lequel elle mentionne les « petites filles noires qui travaillent aux tapis et nous attirent beaucoup de sympathie »

(collection de l'auteur)

Image 30. Carte postale, « Soudan français. A l'Ouvroir, séchage et filage de la laine »

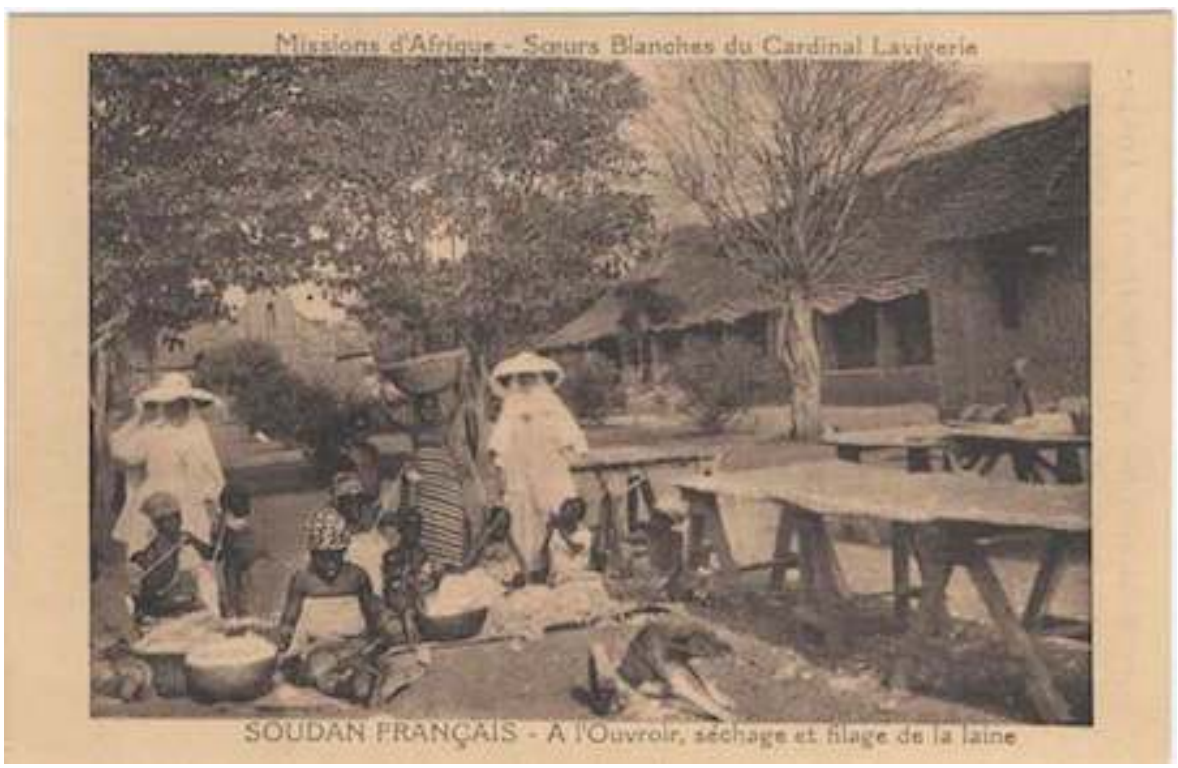

Sans date, Sœurs Missionnaires de Notre-Dame d'Afrique (collection de l'auteur)

Sur la troisième, la présence de deux religieuses debout derrière le petit groupe de fileuses et celle de l'église au fond signalent l'encadrement missionnaire ${ }^{26}$. 
Image 31. Carte postale, "Ouvroir de Ségou. Métiers »

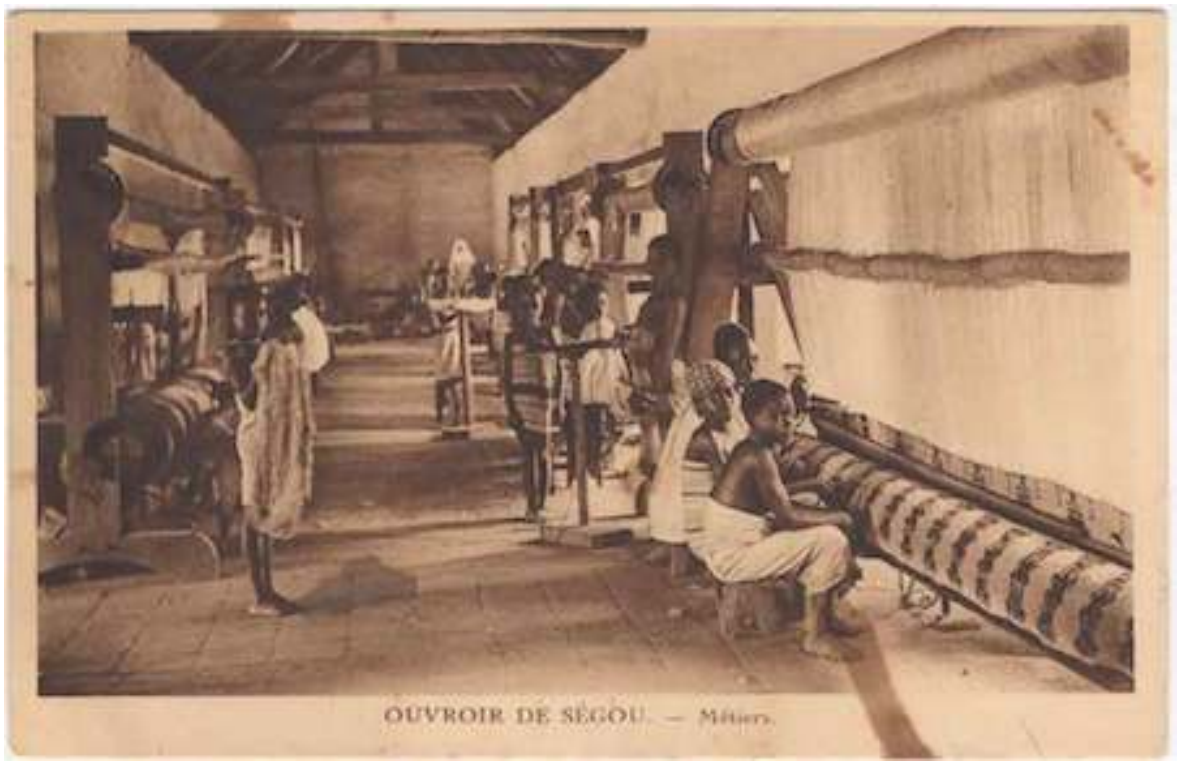

Sans date, Pères Blancs

(collection de l'auteur)

Sur une autre carte postale, c'est l'alignement des métiers à tisser qui organise la perspective et pointe vers le fond de la salle, où l'on devine la présence d'une sœur. Un tapis en cour de réalisation est bien visible sur le premier métier à tisser. La valorisation du travail conduit en effet à la mise en valeur de ses résultats : une demidouzaine de cartes postales sont d'ailleurs éditées pour célébrer le premier tapis sortis de l'ouvroir ou pour inventorier les différents modèles de tapis : modèles Macina et Niafunké.

Image 32. Carte postale, « Missions d'Afrique. Premier tapis sorti de l'ouvroir de Ségou »

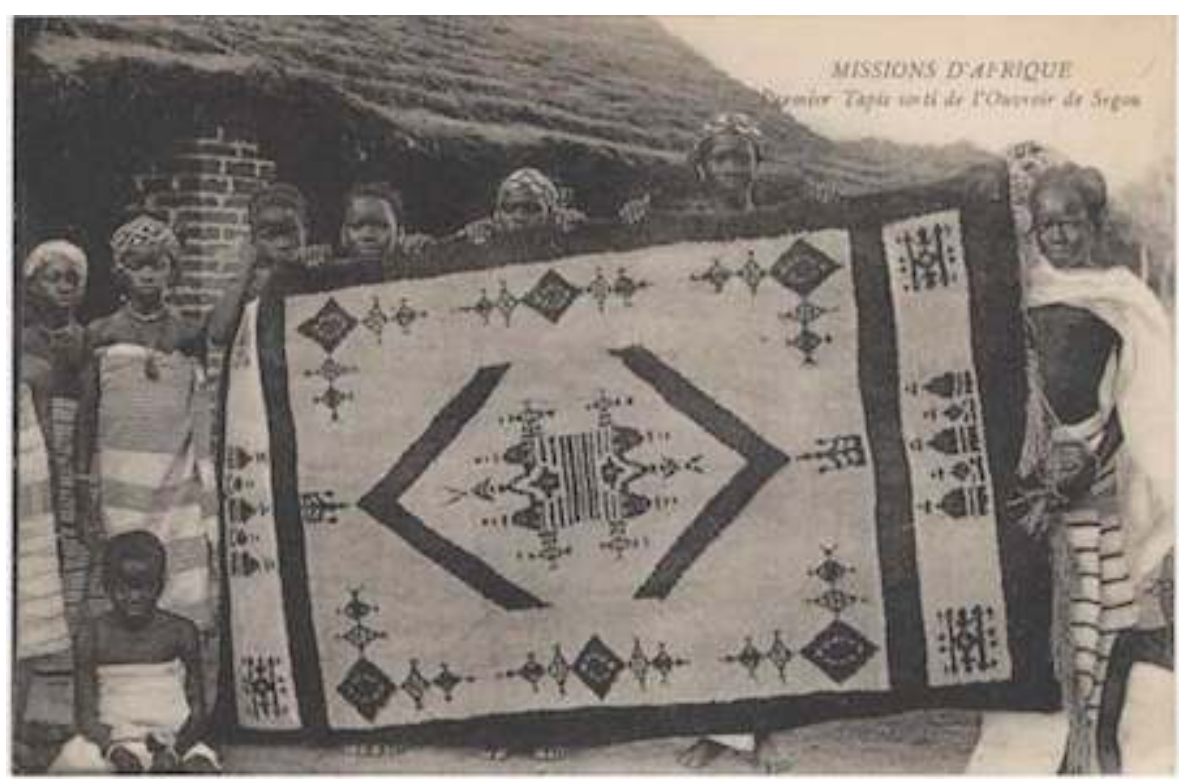

Sans date, Sœurs Missionnaires de Notre-Dame d'Afrique (collection de l'auteur) 
Image 33. Carte postale, "Ouvroir de Ségou. Tapis haute laine. Modèle Macina »

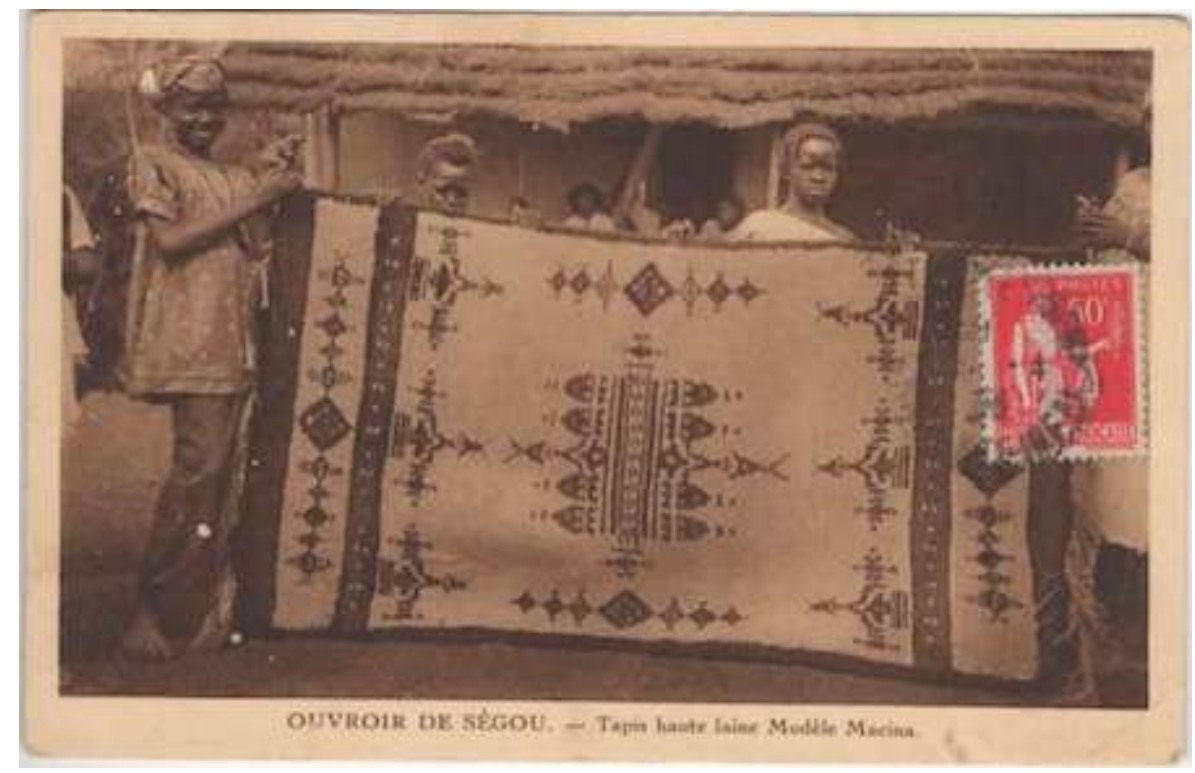

A circulé en 1933, Pères Blancs

(collection de l'auteur)

Image 34. Carte postale, " Ouvroir de Ségou. Tapis haute laine. Modèle Niafunké »

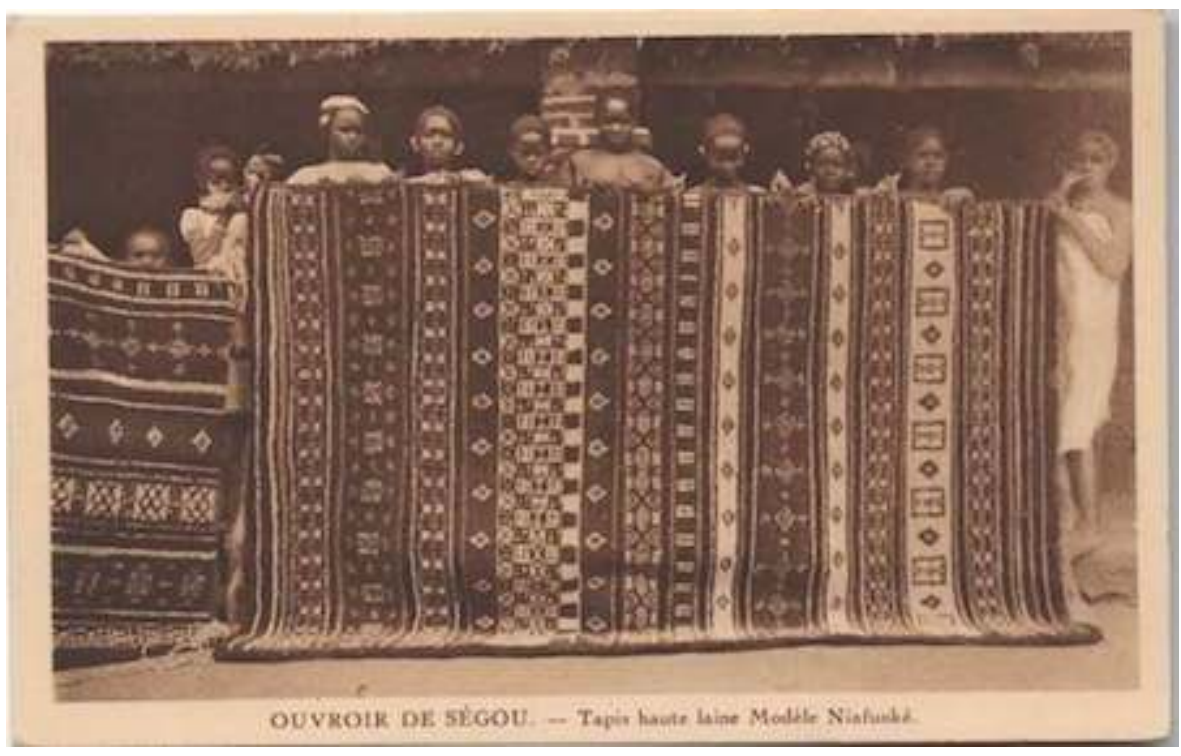

Sans date, Pères Blancs

(collection de l'auteur)

Les ouvrières sont certes présentes pour montrer chaque tapis au photographe mais leurs corps sont entièrement cachés par la surface du textile, qui tend à occuper toute celle de la carte postale. La production de textile ne signale en effet pas seulement la valorisation de l'artisanat local ou les formes d'appropriation des industries occidentales : elle vaut également témoignage de la capacité qu'ont les missionnaires d'agir, par le vêtement, sur le corps des femmes africaines. La machine à coudre et le métier à tisser sont aussi des machines à habiller les populations locales, à commencer 
par les femmes, c'est-à-dire des outils de propagande pour la morale sexuelle missionnaire. Sur les cartes postales présentant les produits sortant de l'ouvroir de Ségou, les corps des ouvrières disparaissent derrière le produit de leur travail. Le corps n'est plus contraint par la machine, il cède la place à la marchandise - sur le plan des images, il y a donc une homologie entre Justine présentant ses cartes postales au photographe et ses consœurs tendant devant elles les lourds tapis en tissage haute laine.

\section{Entre travail et vocation}

61 Entre le catéchisme et la machine à coudre, entre les « ouvrières de Dieu » et celles des ouvroirs, deux conceptions du travail féminin paraissent, à ce stade, s'esquisser, la première relevant de la vocation religieuse, la seconde de l'activité économique plus ou moins contrainte (les jeunes filles étant parfois obligées de se rendre à l'ouvroir, pourtant conçu comme un espace d'émancipation). Envisagé comme un moyen de convertir les jeunes filles et d'accéder à l'intimité des populations locales, le travail féminin est présenté comme point de jonction entre le labeur et l'appel. C'est du moins ce que mettent en scène plusieurs cartes postales consacrées aux "religieuses indigènes » (ou « religieuses noires », pour reprendre les deux expressions en vigueur à l'époque).

Dans l'entre-deux guerres, la création d'un "clergé indigène " devient en effet une priorité, impulsée par les deux encycliques Maximum Illud (Benoît XV), en 1919, et Rerum Ecclesiae (Pie XI), en 1926. Les vocations de femmes ouest africaines se multiplient alors, et plusieurs Instituts africains féminins sont créés. En 1930, les Religieuses Indigènes du Sénégal sont les plus nombreuses (une trentaine), mais l'on compte également neuf Petites Servantes des Pauvres du Dahomey et six Sœurs de Notre-Dame de Guinée (Lesourd 1931a: 291-292). Malgré les discours soulignant la sororité censée animer les religieuses ${ }^{27}$, elles sont les auxiliaires des sœurs missionnaires, de la même manière que ces dernières sont celles des pères. Ces derniers considéraient d'ailleurs que les "religieuses indigènes " pouvaient mieux gagner la confiance des femmes que les sœurs missionnaires. Le père Aupiais, missionnaire au Dahomey, notait par exemple :

«L'œuvre des Sœurs Indigènes était nécessaire depuis longtemps parce que les milieux féminins indigènes offrent moins de prise à l'action des Missionnaires européens que les milieux masculins. [...] La Sœur européenne, même bienfaisante ou munificente, y arrive non sans peine. Les Sœurs indigènes, puisant dans la connaissance des usages des sujets de conversation difficiles à éviter, oblige les femmes païennes à leur faire accueil [...]. Mais il n'y a pas qu'à aborder les femmes païennes, il faut les instruire, répondre à leurs questions. Qui pourra mieux le faire que cette religieuse qui n'ignore rien des secrets d'une langue assez souvent fort habile, qui connaît le genre de raisonnement qu'il faut à ces femmes souvent fort disertes. » (Aupiais, 1929, 583)

La différence culturelle redouble ici la distinction entre milieux masculins et féminins, elle-même étroitement liée aux écarts qu'Aupiais indique entre les compétences respectives des hommes missionnaires, des "sœurs européennes", des "religieuses indigènes » et des «femmes païennes ». Dans la perspective apologétique, le travail féminin est alors conçu comme un moyen de susciter des vocations: apprendre à 
coudre ou à soigner, ce n'est pas seulement devenir une bonne épouse et mère de famille, ce peut être aussi devenir religieuse.

Quelques cartes postales témoignent de cette rencontre entre travail et vocation. Sur l'une d'entre celles que la mission de Ouagadougou a éditées, deux « religieuses noires » sont penchées sur leur machine à coudre, tandis que trois autres font de la dentelle à l'aiguille.

Image 35. Carte postale, « Religieuses noires au travail »

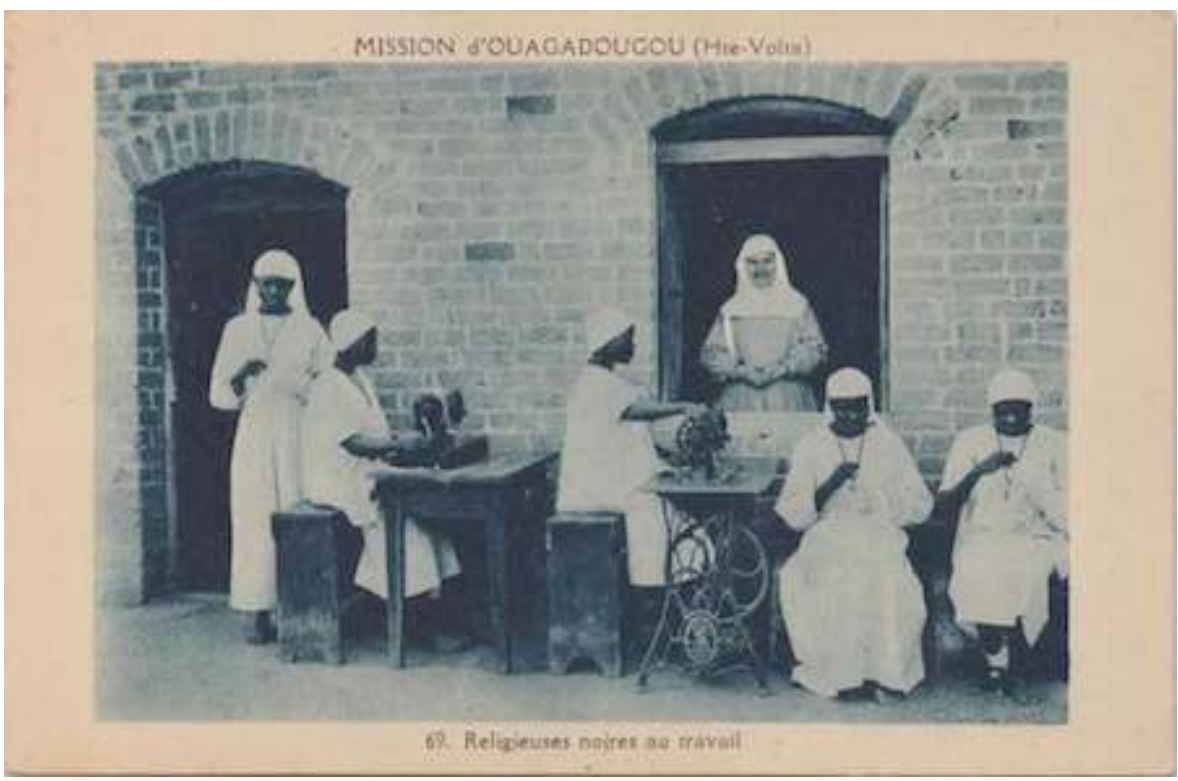

Sans date, Mission de Ouagadougou

(collection de l'auteur)

Une missionnaire européenne est derrière elles, se tenant dans l'encadrement d'une fenêtre. Elle est la seule qui regarde, souriante, le photographe - image dans l'image qui fait du buste de la religieuse comme un portrait accroché au mur. Seule la tenue des cinq jeunes femmes et la légende de la carte postale permettent de les distinguer des ouvrières photographiées à l'ouvroir: elles en partagent la posture et les gestes. La légende de la carte, «Religieuses noires au travail », signale la difficile distinction entre travail et vocation et souligne la différence de statut entre les cinq sœurs « indigènes » et la sœur missionnaire, qui, elle, n'est pas «au travail». Cette distinction se joue également dans l'image, notamment par l'opposition entre espace extérieur et intérieur ou entre regard au photographe et à l'ouvrage - indices de subjectivation de la religieuse européenne et de subordination de ses consœurs.

La mise en scène du travail des "religieuses indigènes » témoigne mieux encore des relations entre vocation religieuse et métiers du soin (soins infirmiers et puériculture). L'entre-deux-guerres est en effet le moment où ces activités se professionnalisent en métropole (création du brevet de capacité d'infirmière diplômée d'état en 1922, qui devient obligatoire en 1943), tandis qu'elles sont encore largement prises en charge par les missionnaires aux colonies (Dufourcq, 1993, 572-574). Les " religieuses indigènes " sont donc formées comme infirmières ou puéricultrices, dans un contexte de pénurie de médecins et d'infirmiers coloniaux. Infirmière est, avec institutrice, l'un des deux métiers considérés comme conformes aux compétences féminines (Barthélémy, 2002, 
37). Sœur Marie-André du Sacré-Cœur notait par exemple, à propos des religieuses indigènes, que « les œuvres qui leur sont confiées bénéficient de tout leur dévouement d'infirmières ou d'éducatrices, et l'élévation de leur vie morale prouve que le plus noble idéal n'est pas inaccessible à la femme noire jusqu'ici asservie par des siècles de paganisme " (Marie-André du Sacré-Cœur, 1940, 23). Plusieurs cartes postales les montrent donc en train de soigner des malades.

Image 36. Carte postale, "Religieuse noire soignant les malades »

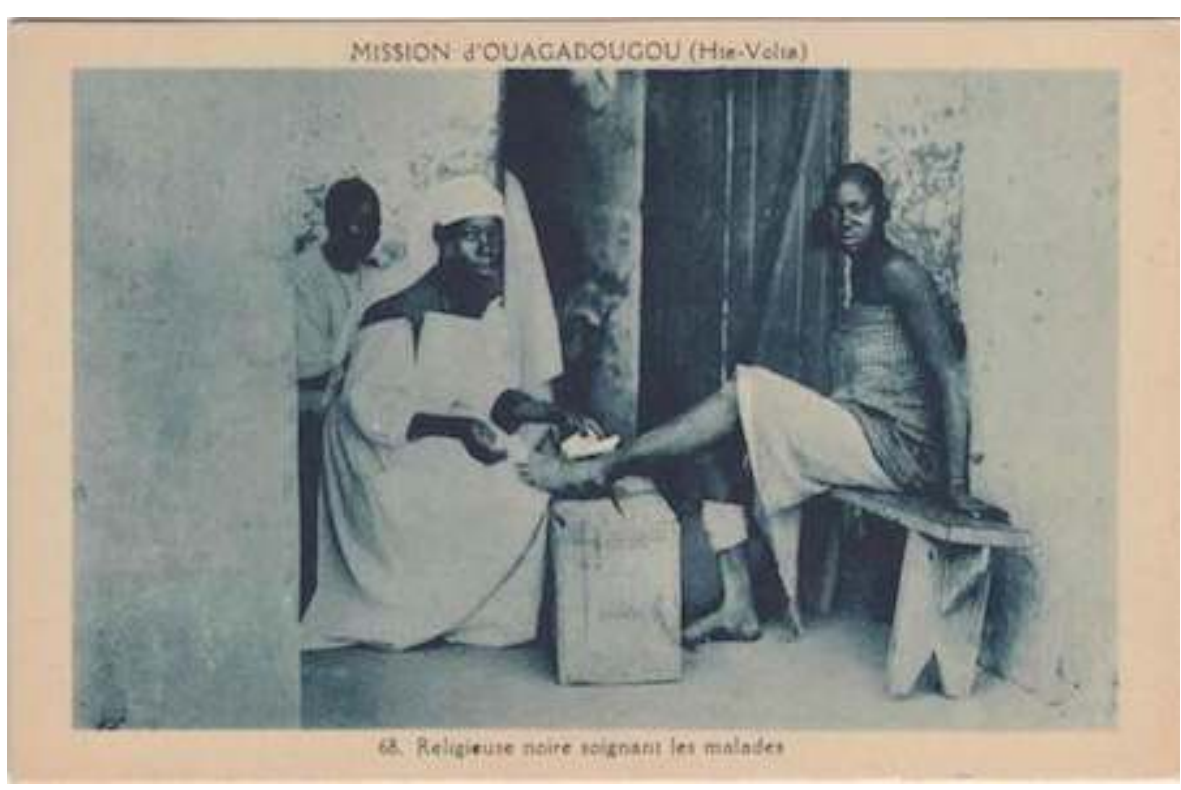

Sans date, Mission de Ouagadougou

(collection de l'auteur) 


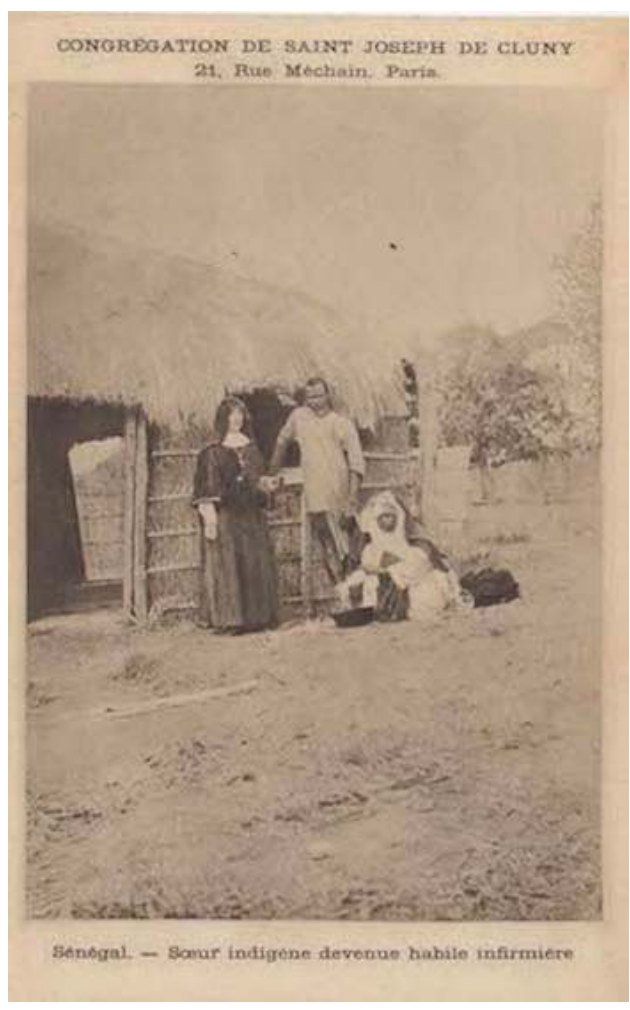

Sans date, Congrégation de Saint Joseph de Cluny (collection de l'auteur)

67 La posture des religieuses est ici la même que celle de leurs consœurs européennes : elles sont généralement agenouillées pour être à la hauteur du patient. Sur la seconde carte postale, le lavement des pieds du malade peut évoquer le geste très largement représenté dans les images de piété du Christ se mettant à genou pour laver les pieds de ses Apôtres la veille de sa crucifixion. L'humilité du geste célèbre alors les services rendus par les religieuses aux plus démunis : la mise en scène des soins s'oppose ici au modèle visuel de la leçon.

Les deux cependant se rencontrent autour de la puériculture, qui articule pratiques de soins et transmissions de savoirs. Une partie du travail des religieuses européennes consiste à enseigner les "soins maternels ", prenant argument de la forte mortalité infantile. Si le paradoxe de cette ambition, qui consiste à confier à des femmes n'ayant pas d'enfants le rôle de former celles qui en ont, a déjà été noté (Arrington, 2010 ; Bouron, 2014), il est frappant cependant que les sœurs « indigènes » se voient attribuer les mêmes objectifs. Cette tendance se situe dans le contexte plus général de formation de sages-femmes et de puéricultrices africaines dans les colonies (Allman, 1994 ; Hugon, 2004 ; Barthélémy, 2004 et 2010). Les cartes postales missionnaires figurant des crèches donnent cependant à voir les soins maternels des religieuses sous un angle spécifique : elles permettent de fournir des preuves visuelles des pratiques d'abandon d'enfants (traitement jugé inhumain et présenté alors comme étant caractéristique des populations locales) tout en favorisant l'empathie des récepteurs de l'image, appelé à participer, par des dons, au sauvetage de ces orphelins. Les religieuses « indigènes » se retrouvent en position d'assurer à ces enfants les soins maternels qui leur manquent. Sur une carte postale des Sœurs de Notre-Dame des Apôtres, on voit ainsi une religieuse 
européenne entourée de deux auxiliaires africaines portant chacune, symétriquement, un nourrisson dans les bras.

Image 38. Carte postale, «Ibadan (Bénin). Petits enfants abandonnés recueillis par les Sœurs Missionnaires »

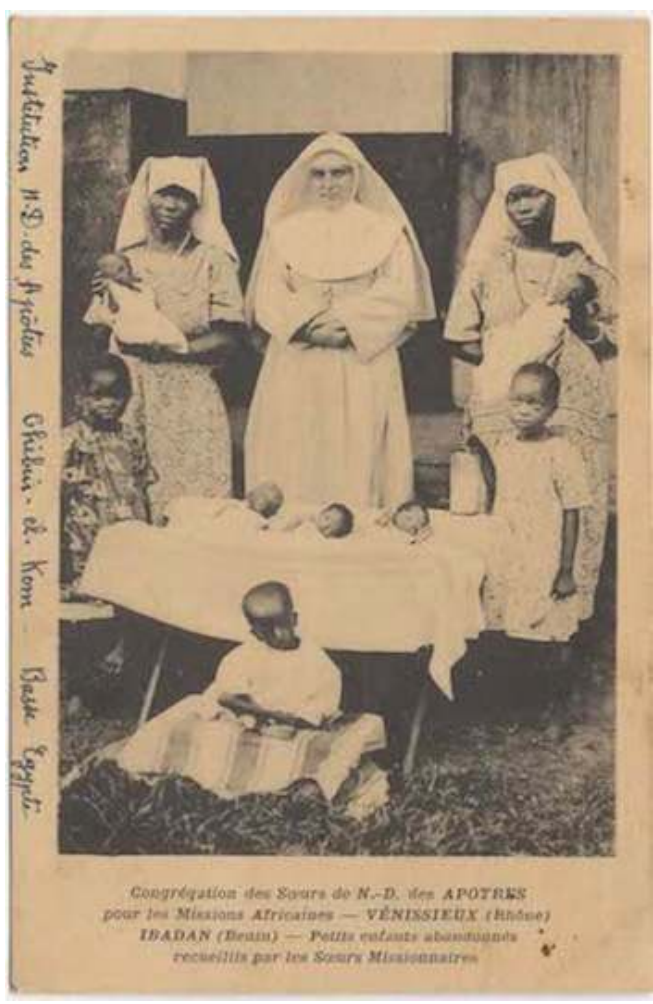

Sans date, Sœurs Missionnaires de Notre-Dame des Apôtres (collection de l'auteur)

Six autres nouveau-nés ou jeunes enfants prennent également la pose, respectant la symétrie organisée par le photographe. La maternité devient le modèle paradoxal de la rencontre entre sœurs européennes et africaines, définissant les normes de la féminité en opposant les femmes " païennes » aux « bonnes mères » que seraient les religieuses. Cette idéologie maternaliste, étroitement liée au projet impérialiste, participe à la reconfiguration des rapports sociaux de sexe (Davin, 1978; Alman, 1994). Evoquée visuellement ici, elle sert d'argument en faveur de la prise en charge, par les religieuses « indigènes » et à travers les enfants, de l'avenir des colonies.

\section{Conclusion}

En décembre 1931, Justine et ses consœurs sont de retour au Soudan français. Elles racontent leur voyage à leurs proches et leur montrent des photographies de Paris (des cartes postales?) qu'elles ont ramenées avec elles. Ces images qui circulent en sens inverse s'inscrivent elles aussi dans une propagande missionnaire, cette fois à destination de la population locale. Dans une lettre qu'elles auraient dictée, collectivement, à Sœur Marie-André du Sacré-Cœur, adressée aux visiteurs de l'Exposition coloniale, Justine et ses consœurs témoignent de l'accueil qu'elles reçoivent à leur retour et expliquent : 
"Ce qu'il y a de plus beau à Paris, ce sont les églises. Oui, tous les Français sont des "fama" (riches), car ils ont de grandes églises bien plus belles que celles du Soudan. Nous montrons à nos parents les photographies de Montmartre, de N.-D. des Victoires [...]. Nos parents se font à peine une idée des choses merveilleuses que nous racontons. » (Marie-André du Sacré-Cœur, 1932, 104)

71 Les trois images qui accompagnent ce courrier ne sont cependant ni des vues de Paris, ni des photographies de leur retour, mais celles qui ont été prises à l'occasion de l'Exposition. La première est celle qui a été diffusée sous forme de carte postale accompagnée de la légende "Au travail» (illustration 3). Les images ici encore témoignent moins du récit que les jeunes femmes font de leur expérience, de leur subjectivité, que de la mise en scène auxquelles elles ont participé pour les visiteurs de l'Exposition. Le travail des images occulte le sujet collectif du récit - auquel une sœur blanche prête, sinon impose, sa voix.

72 C'est l'une des caractéristiques essentielles des cartes postales missionnaires étudiées ici : elles rendent certes visibles les femmes en situation coloniale, mais en focalisant sur les images du collectif plutôt que des individus (solidarité entre religieuses et colonisées affichée à des fins de propagande), localisant son apparition dans l'agencement des corps (notamment dans leur rapport à la machine). L'ambivalence des rencontres missionnaires, entre émancipation et domination, ne cesse pour sa part d'apparaître sous forme indicielle, à travers divers procédés figuratifs : la récurrence des présences missionnaires, l'objectification des corps mécanisés ou confondus avec les produits de leur travail, l'anonymisation collective, les analogies visuelles entre la leçon de catéchisme et les travaux d'aiguille, la mise en scène d'une continuité entre les sœurs européennes et africaines...

73 La domination même se donne à voir doublement. D'une part, le travail féminin passe par la discipline des corps qu'imposent conjointement les religieuses et les machines. Pour les missionnaires, conquête morale des femmes, mécanisation des corps et pénétration des espaces domestiques constituent des dispositifs disciplinaires permettant d'agir sur l'intimité des femmes. Sur ce plan, ils s'inscrivent parfaitement dans les rapports coloniaux entre modes d'administration des populations et exercice d'un contrôle sur les corps, les sexualités et les espaces domestiques (Camiscioli, 2013). D'autre part, le travail des images repose sur les contraintes qu'exercent le photographe et son appareil sur les corps des sujets photographiés : prendre la pose revient à faire comme si le corps était au travail, à convoquer pour la photographie les gestes et les postures de la leçon, du labeur ou du soin. C'est dans cette double perspective analytique (les images du travail envisagées comme des dispositifs disciplinaires sur un plan à la fois indiciel et iconique) que peut s'écrire l'histoire visuelle des rencontres missionnaires. 


\section{BIBLIOGRAPHIE}

Albert-Llorca M. (1995), « Les fils de la Vierge. Broderie et dentelle dans l'éducation des jeunes filles », L'Homme, tome 35, n 133, p. 99-122.

Allman J. (1994), « Making Mothers: Missionaries, Medical Officers and Women's Work in Colonial Asante, 1924-1945 », History Workshop, n 38, p. 23-47.

Aupiais F. (1929), «Les religieuses indigènes en Afrique d'après l'autobiographie de Sœur Marguerite-Marie », Les Missions catholiques, n³000, p. 583-590.

Anonyme (1925), « Congrégation des Sœurs missionnaires de Notre-Dame d'Afrique », Revue illustrée de l'Exposition missionnaire vaticane, 2e année, $n^{\circ} 21$, p. 661.

Anonyme (1931), De la Côte des Esclaves aux rives du Nil, Paris-Lyon-Vénissieux, Librairie E. VitteSœurs missionnaires de Notre-Dame des Apôtres.

Anonyme (1935), 7 ans de vie soudanaise, Lyon, Edition G.-L. Arlaud.

Arrington A. L. (2012), « Making sense of Martha: single women and mission work », Social Sciences and Missions, vol. 23, $\mathrm{n}^{\circ}$ 2, p. 276-300.

Barthélémy P. (2002), « La professionnalisation des Africaines en AOF (1920-1960) », Vingtième Siècle. Revue d'histoire, $\mathrm{n}^{\circ}$ 75, p. 35-46.

Barthélémy P. (2004), « Sages-femmes africaines diplômées en AOF des années 1920 aux années $1960 »$, in A. Hugon (dir.), Histoire des femmes en situation coloniale, Paris, Karthala, p. 119-145.

Barthélémy P. (2010), Africaines et diplômées à l'époque coloniale (1918-1957), Rennes, PUR.

Barthélémy P. Jézéquel J.-H. (2007), « Marier "les demoiselles frigidaires" et les "mangeurs de craies" : l'idéal du ménage lettré et l'administration coloniale en Afrique Occidentale Française (AOF) », in Goerg O. (dir.), Perspectives historiques sur le genre en Afrique, Paris, L'Harmattan, 2007, p. 77-96.

Beaupin E. (1929), Les missions, Paris, Librairie Bloud et Gay.

Belmenouar S. et Combier M. (2007), Bons baisers des colonies. Images de la femme dans la carte postale coloniale, Paris, Editions alternatives.

Bergougniou J.-M. (2004), « Des petites soudanaises à l'exposition de Vincennes », Gavroche. Revue d'histoire populaire, 23e année, $\mathrm{n}^{\circ} 137$, p. 6-11.

de Benoist, J.-R. (1984), Église et pouvoir colonial au Soudan français. Administrateurs et missionnaires dans la boucle du Niger (1885-1945), Paris, Karthala.

Bobin F. (2003), « Sœurs blanches et femmes voltaïques. Regards croisés sur l'ouvroir de Ouagadougou (1917-1954) », IN H. d'Almeida-Topor, M. Lakroum et G. Spittler (dir.), Le travail en Afrique noire. Représentations et pratiques à l'époque contemporaine, Paris, Karthala, p. 261-282.

Bouron, J.-M. (2012), « Le paradigme médical en milieu catholique: offre sanitaire missionnaire et demande de santé en Haute-Volta (actuel Burkina Faso) », Histoire et missions chrétiennes, $\mathrm{n}^{\circ}$ 1, p. 103-136.

Bouron J.-M. (2014), « Dominées ou dominantes ? Les Sœurs Blanches dans l'ambivalence des logiques d'autorité (Haute-Volta et Gold Coast, 1912-1960) », Histoire, mondes et cultures religieuses, $\mathrm{n}^{\circ} 30$, p. 51-73. 
Bowie F., Kirkwood D. et Ardener S. (eds), 1993, Women and Missions : Past and Present. Anthropological and Historical Perceptions, Providence-Oxford, Berg.

Corbey R. H. A. (1988), « Alterity: The colonial nude », Critique of Anthropology, VIII (3), p. 75-92. Coffin J. (1994), « Credit, Consumption, and Images of Women's Desires: Selling the Sewing Machine in Late Nineteenth-Century France ", French Historical Studies, n 3, p. 749-783.

Coffin J. (1996), « Production, Consumption, and Gender: The Sewing Machine in France », in L. Frader et S. Rose (eds), Gender and the Reconstruction of European Working-Class History, Ithaca, Cornell University Press, p. 111-141.

Cunningham V. (1993), « God and Nature Intended You for a Missionary's Wife : Mary Hill, Jane Eyre and Other Missionary Women in 1840s ", in F. Bowie, D. Kirkwood et S. Ardener S. (eds), Women and Missions : Past and Present. Anthropological and Historical Perceptions, Providence-Oxford, Berg, p. 85-105.

Curtis S. A. (2010a), «À la découverte de la femme missionnaire », Histoire et missions chrétiennes, $\mathrm{n}^{\circ} 16$, p. 5-18.

Curtis S. A. (2010b), Civilizing Habits. Women and the Revival of French Empire, Oxford University Press, Oxford.

Davin A. (1978), « Imperialism and motherhood », History Workshop, n 5, p. 9-57.

Diarra P. (2009), Cent ans de catholicisme au Mali. Approche anthropologique et théologique d'une rencontre (1888-1988), Paris, Karthala.

Deflandre C. (2006), « Carte postale », in L. Gerverau (dir.), Dictionnaire mondial des images, L. Gervereau (dir.), Paris, Nouveau Monde éditions, p. 171-176.

Dubois H. (1932), Traité de missiologie pratique. Le répertoire africain, Rome, Sodalité de S. Pierre Claver.

Dufourcq I. (1993), Les congrégations religieuses féminines hors d'Europe de Richelieu à nos jours. Histoire naturelle d'une diaspora, quatre tomes, Paris, Librairie de l'Inde éditeur.

Follereau R. (1945), Sur les routes de la charité. 22000 kilomètres au-dessus de l'océan et à travers la brousse africaine avec deux sœurs missionnaires, Paris-Lyon, Vitte.

Foster E. A. (2010), « "En mission, il faut se faire à tout". Les sœurs de l'Immaculée Conception de Castres au Sénégal, 1880-1900 », Histoire et missions chrétiennes, n 16, p. 73-108.

Fraisse G. et M. Perrot (dir.), 2002, Histoire des femmes en Occident. IV. Le XIXe siècle, Paris, Plon. Frugoni C (1993), Francesco e l'invenzione delle stimmate : una storia per parole e imagini fino a Bonaventura e Giotto, Turin, Einaudi.

Gorju J. (1915), La Côte d'Ivoire chrétienne, Lyon-Paris, Librairie Catholique Emmanuel Vitte.

Goyau G. (1933), La femme dans les Missions, Paris, Flammarion.

Guilcher R (s. d), Les Missions Africaines de Lyon, Lyon, Procure des Missions Africaines de Lyon.

Higonney A. (2002), « Femmes et images. Représentations », in G. Fraisse et M. Perrot (dir.), Histoire des femmes en Occident. IV. Le XIXe siècle, Paris, Plon, p. 335-384.

Huber M. T. et Lutkehaus N. (eds), 1999, Gendered Missions. Women and Men in Missionary Discourse and Practice, University of Michigan Press. 
Hugon A. (1997), « Religions et missions », in N. Bancel, P. Blanchard et F. Delabarre (dir.), Images d'Empire, 1930-1960. Trente ans de photographies officielles sur l'Afrique française, Paris, Editions de la Martinière-La Documentation française, 1997, p. 214-229.

Hugon A. (2004), « La redéfinition de la maternité en Gold Coast, des années 1920 aux années 1950 : projet colonial et réalités locales », in A. Hugon (dir.), Histoire des femmes en situation coloniale, Paris, Karthala, p. 145-171.

Langewiesche K. (2012), « Émancipation et obéissance : Religieuses catholiques au Burkina Faso durant un siècle ", Autrepart, $\mathrm{n}^{\circ}$ 61, p. 117-136.

Lena, «Le statut légal de la femme chrétienne dans l'Afrique païenne », in Union missionnaire du clergé, Les Missions catholiques et l'œuvre de civilisation. Conférences données à l'Institut catholique de Paris, 1927-1928, Paris, Librairie Bloud et Gay, 1929 : 67-77.

Lesourd P. (dir.), 1931a, L'année missionnaire 1931, Paris, Desclée de Brouwer \& Cie.

Lesourd P. (1931b), L'œuvre civilisatrice et scientifique des missionnaires catholiques dans les colonies françaises, Paris, Desclée de Brouwer \& Cie.

Lolom, O. (2012) « Le fonds photographique des Missions Catholiques », in J. Pirotte, C. Sappia et $\mathrm{O}$. Servais (dir.), Images et diffusion du christianisme. Expressions graphiques en contexte missionnaire XVIe-XXe siècles, Paris, Karthala, p. 261-273

Marie-André Du Sacré-Cœur S. (1932), « Le retour au Soudan », Annales de la propagation de la foi, $n^{\circ} 622$, p. $102-105$

Marie-André Du Sacré-Cœur S. (1939), La femme noire en Afrique Occidentale, Paris, Payot.

Marie-André Du Sacré-Cœur S. (1940), « Vie familiale de la femme noire », in La femme noire dans la société africaine (conférences données à l'Institut Catholique de Paris, 1938-1939), Paris, Bibliothèque de l'Union Missionnaire du Clergé, p. 1-29.

Marks S. (1994), Divided Sisterhood. Race, class and gender in the South African nursing profession, New York, St. Martin's.

Martin M. (1980), « La rationalisation du travail ménager en France dans l'Entre-deux-guerres », Culture technique, $\mathrm{n}^{\circ}$ 3, p. 157-165.

Martin M. (1987), « Ménagère, une profession ? Les dilemmes de l'entre-deux-guerres », Le Mouvement social, $\mathrm{n}^{\circ} 140$, p. 89-106.

Pellegrin N. (1999), « Les vertus de "l'ouvrage". Recherches sur la féminisation des travaux d'aiguille (XVIe-XVIIIe siècles) », Revue d'histoire moderne et contemporaine, tome $46, \mathrm{n}^{\circ} 4, \mathrm{p}$. 747-769.

Perrot M. (1978), « Machines à coudre et travail à domicile », Mouvement Social, n 105, p. 161-164. Peyrière M. (1996), «L'industrie de la machine à coudre, 1830-1914 », in L. Bergeron (dir.), La Révolution des aiguilles, Habiller les Français et les Américains, XIXe et XXe siècles, Éditions EHESS, p. 95-114.

Piette V. et Gubin E. (2001), « Travail ou non-travail ? Éssai sur le travail ménager dans l'entredeux-guerres ", Revue belge de philologie et d'histoire, tome 79, fasc. 2, 2001, p. 645-678.

Pirotte J. (2005), « L'espace et le temps vécus en mission. De la gestion du quotidien à la construction symbolique ", in J. Pirotte (dir.), Les conditions matérielles de la mission. Contraintes, dépassements et imaginaires, XVIIe-XXe siècles, Paris, Karthala, p. 17-44. 
Pirotte J., Sappia C. et Servais O. (dir.), 2012, Images et diffusion du christianisme. Expressions graphiques en contexte missionnaire XVIe-XXe siècles, Paris, Karthala.

Prevost E. E. (2010), The Communion of Women: Missions and Gender in Colonial Africa and the British Metropole, New York, Oxford University Press.

Raison-Jourde F. (1993), « Image missionnaire française et propagande coloniale », dans N. Bancel, P. Blanchard et L. Gervereau (dir.), Images et colonies. Iconographie et propagande coloniale sur l'Afrique française de 1880 à 1962, Nanterre-Paris, BDIC-ACHAC, p. 50-57.

Randau R. (1940), « La femme noire dans la coutume indigène », in La femme noire dans la société africaine (conférences données à l'Institut Catholique de Paris, 1938-1939), Paris, Bibliothèque de l'Union Missionnaire du Clergé, p. 57-104.

Richemont S. (2011), « Contribution de la Mission des Pères Blancs d'Ouagadougou à l'iconographie de la Haute-Volta coloniale », Images \& Mémoire, bull. n² 29, p. 20-25.

Rillon O. (2012), «Ces femmes que je ne saurais voir. Les dimensions sexuées de l'enquête de terrain en histoire ", Hypothèses, $\mathrm{n}^{\circ} 15$, p. 41-51.

Rogers R. (2009), « Genre, mission et colonisation », dans D. Borne et B. Falaize (dir.), Religions et colonisation. Afrique-Asie-Océanie-Amériques (XVIe-XXe siècle), Paris, L’Atelier, p. 93-100.

Saint-Martin I. (2003), Voir, savoir, croire. Catéchismes et pédagogie par l'image au XIXe siècle, Paris, Honoré Champion.

Sanou Doti B. (1991), « Sœur Marie-André du Sacré-Cœur, Sœur Blanche. Son action en faveur des femmes africaines jugées par ses consœurs missionnaires de la colonie de Haute-Volta (1932-1939) ", in Femmes en mission. Actes de la XIème session du CREDIC à Saint Flour (août 1990), Lyon, Editions lyonnaises d'art et d'histoire, p. 247-268.

Silla E. (1988), "People Are Not the Same". Leprosy and Identity in Twentieth-Century Mali, Portsmouth, N.H.

Strebler J. (s. d.), Au service de l'Afrique noire. Avec les Petites Servantes du Sacré-Cour, missionnairescatéchistes des Noirs d'Afrique, s.e.

Tirefort A. (2009), « Une mise en scène imagée ? La carte postale et la colonie de Côte d'Ivoire dans le premier quart du vingtième siècle ", in I. Ndaywel è Nziem et E. Mudimbe-Boyi (eds), Images, mémoires et savoirs. Une histoire en partage avec Bogumil Koss Jewsiewicki, Paris, Karthala, p. 301-331.

Verdier Y. (1979), Façons de dire, façons de faire. La laveuse, la couturière, la cuisinière, Paris, Gallimard.

Vokes R. (2010), « Reflections on a complex (and cosmopolitan) archive : postcards and photography in early colonial Uganda, c. 1904-1928», History and Anthropology, 21-4, p. 375-409.

Wilbois, J. (1938), L'action sociale en pays de missions, Paris, Payot.

\section{NOTES}

1. Neuf d'entre elles venaient de la mission de Ouagadougou et six de la mission de Ségou, située dans la colonie voisine du Soudan français. Les noms coloniaux des territoires concernés par cet article sont utilisés uniquement pour des raisons de contextualisation historique. Sur la présence de ces quinze jeunes femmes à l'Exposition coloniale de 1931, voir Bergougniou, 2004. 
2. Opposer les cartes postales missionnaires aux cartes postales coloniales pourrait permettre d'insister sur de telles différences. Les secondes mettent par exemple très largement en scène la nudité et l'érotisme (Corbey, 1988) quand les premières donnent à voir des femmes habillées. De même, les cartes postales coloniales montrent généralement des femmes seules, individuées bien qu'anonymisées, dans un dispositif propice à l'évocation (pour le regardeur) d'un face-à-face érotique (la violence faite au sujet photographié se nouant précisément dans la manipulation du pouvoir de l'image, dans l'attribution d'une agentivité à la figure au détriment du sujet); les cartes postales missionnaires donnent le plus souvent à voir des collectifs de femmes. Insister sur ces différences aurait cependant pour conséquence d'occulter le caractère colonial des cartes postales missionnaires de l'époque. Analyser les cartes postales missionnaires comme une souscatégorie des cartes postales coloniales est sans doute plus justifié, mais soulève d'autres difficultés épistémologiques, portant notamment sur la périodicité.

3. Cet argument était d'ailleurs central dans la création des différents instituts féminins à partir de la seconde moitié du 19e siècle, en conformité « avec une idéologie montante qui soutenait que le foyer familial était la clef de l'intégration culturelle » (Curtis, 2010, 8).

4. Docteure en droit, Sœur Marie-André du Sacré-Cœur a enquêté sur la condition des femmes en AOF, de 1932 à 1936, essentiellement en Haute-Volta. Elle militait notamment contre le mariage forcé (voir Sanou Doti, 1991).

5. Les termes employés ici sont utilisés de manière récurrente dans les discours missionnaires de l'époque.

6. Sur le genre masculin du mot « missionnaire », voir aussi Curtis, 2010a.

7. Voir aussi Curtis, $2010 \mathrm{~b}$.

8. Pour une histoire synthétique de la carte postale, voir Deflandre, 2006.

9. L'analyse de telles images, comme dans d'autres perspectives le recours à l'histoire orale, peut donc permettre de « contourner le filtre sexué des archives» (Rillon, 2012, 41). Cela revient par ailleurs à s'inscrire dans le programme d'histoire visuelle des femmes esquissé par Geneviève Fraisse et Michelle Perrot à partir du constat selon lequel «la femme n'existe jamais sans son image » (Fraisse et Perrot, 2002, 16).

10. Il n'est pas possible, dans le cadre de cet article, de présenter les cartes postales missionnaires mettant en scène le travail féminin de manière exhaustive. Le choix a néanmoins été fait de s'appuyer sur un corpus représentatif mais aussi conséquent, afin de rendre compte du caractère relativement massif de leur production dans l'entre-deux-guerres et des thèmes privilégiés.

11. Pour ce qui concerne la France, trois sociétés missionnaires se partagent l'essentiel de l'Afrique de l'Ouest, selon un découpage géographique assez précis : les Pères blancs et les Sœurs blanches, venus d'Afrique du Nord, ont en charge le Soudan français, la Haute-Volta, la Société des missions africaines de Lyon (SMA) occupe le golfe de Guinée avec les sœurs de Notre-Dame des Apôtres, les pères du Saint-Esprit installent leurs postes missionnaires du Sénégal à la Sierra Leone, ainsi qu'en Afrique Equatoriale Française. Ils sont, notamment, secondés par des sœurs de Saint-Joseph de Cluny et, dans une moindre mesure, des sœurs de Notre-Dame de l'Immaculée Conception. Plusieurs postes sont donc installés dans des colonies anglaises (Côte d'Or et Sierra Leone notamment) ainsi qu'au Liberia (où l'on compte, au début des années 1930, plusieurs missionnaires de la Société des missions Africaines de Lyon, mais uniquement des hommes).

12. Fondée en 1995 par un collectif de chercheurs et collectionneurs pour valoriser la richesse iconographique produite à propos des sociétés africaines, cette association publie un bulletin trimestriel dont plusieurs articles sont régulièrement consacrés aux cartes postales et, moins souvent, aux images missionnaires.

13. http://idpao.com/index.php

14. Les cartes postales éditées par les missions ne donnent donc pas toutes à voir des missionnaires. Par exemple, sur les 85 cartes postales éditées par la mission de Ouagadougou, 
$19 \%$ seulement concernent les missionnaires, dont 8 qui sont consacrées aux religieuses et à leurs élèves ou apprenties (Richemont, 2011).

15. La tournée apostolique fournit en outre quelques rares cartes postales où les religieuses sont photographiées en présence d'hommes. C'est un homme par exemple qui conduit un petit groupe d'entre elles en pirogue sur la lagune (illustration 5). C'est un homme encore qui emporte en tournée une sœur missionnaire de Notre-Dame des Apôtres en tirant son pousse-pousse (illustration 6).

16. Il n'existe en effet pas d'image missionnaire en soi. C'est bien l'entreprise de qualification ou de requalification des images qui permet de les classer dans cette catégorie problématique. Elle peut trouver des arguments dans des indices visuels, mais aussi dans les différents contenus textuels qui accompagnent l'image (légendes et explications imprimées ou manuscrites) et dans les renseignements concernant leur production, leur diffusion ou leur réception.

17. Les secondes, davantage destinées aux enfants en France et aux adultes dans les pays de mission, ont pris une importance de plus en plus grande au cours du XIX ${ }^{\mathrm{e}}$ siècle (Saint-Martin, 2003).

18. Sur ce double aspect, voir Pirotte, Sappia et Servais, 2012.

19. Pour des raisons éthiques, le choix est fait ici de ne pas reproduire la sixième carte postale du carnet édité par l'đEuvre Pontificale de la Propagation de la Foi sous le titre «Les catéchistes dans les missions ». Cette carte, qui a pour légende "Le catéchisme aux lépreux chez les Sœurs Blanches », figure un groupe de neufs lépreux apparemment jeunes et fortement mutilés encadrés par deux religieuses. Les premiers ont la tête couverte et parfois la face en partie cachée par un pan de tissu, ce qui accroît le contraste avec les visages voilés de blanc des deux sœurs. Tous regardent le photographe.

20. Sur cette imagerie médiévale, voir Frugoni, 1993.

21. Une partie de cet enseignement était consacrée à la puériculture ou aux « soins maternels ». Cet aspect est peu représenté dans les cartes postales (et ne sera donc pas développé dans cet article). Pour les missiologues de l'époque, c'était surtout à travers lui que « les Missions, plus que tous les autres groupes, peuvent atteindre les noirs jusque dans leur vie la plus intime » (Dubois, 1932, 152).

22. Il faudrait néanmoins apporter quelques nuances, indiquer les variations en fonction des congrégations ou des territoires concernés. Les Sœurs Bleues de Castres, par exemple, jouissent au Sénégal d'une autonomie plutôt exceptionnelle (Foster, 2010).

23. Intervention de Sœur Marie-André du Sacré-Cœur lors de la semaine sociale de Marseille, en juillet-août 1930, sur « l'enseignement ménager », citée par Lesourd (1931b, 79).

24. Au premier plan, au pied de la machine à coudre, deux jeunes enfants sont en train de jouer avec une poupée. Les poupées étaient alors habituellement utilisées dans le cadre de l'enseignement de la puériculture.

25. Intervention de Sœur Marie-André du Sacré-Cœur lors de la semaine sociale de Marseille, en juillet-août 1930, sur « l'enseignement ménager », citée par Lesourd (1931b, 79).

26. La présence fortuite d'un chien qui se gratte en premier plan, au centre, rend cette image curieuse par ailleurs. Le choix a été fait de ne pas retoucher la photographie (pratique courante à l'époque), ce qui dénote un certain souci de réalisme. Les éléments hélas manquent pour une interprétation fine de cette étrange présence canine.

27. Raoul Follereau écrit par exemple, au sujet des religieuses «indigènes » : « Pour Dieu, point de couleurs, point de races, point de frontières, point de castes ni de classes. [...] toutes les jeunes filles qui se destinent à Son service et à Sa gloire sont liées par des liens plus forts que ceux du sang, plus doux que ceux des affections humaines : elles sont vraiment, pleinement Sœurs » (Follereau, 1945, 160). 


\section{RÉSUMÉS}

Basé sur un corpus de cartes postales missionnaires datant des années 1920 et 1930 et consacrées à l'Afrique de l'Ouest, cet article vise à analyser la transmission d'une certaine conception du travail féminin dans le contexte missionnaire colonial. Les femmes au travail, dans cet article, sont donc aussi bien les femmes missionnaires que les femmes africaines, dans la mesure où le travail est précisément ce qui les rassemble sur les images, voire dans leur expérience de la féminité. Outre leur mission d'évangélisation, une part essentielle de l'activité des religieuses consistait à transmettre un ensemble de connaissances et de savoir-faire en matière de travail manuel, d'éducation ménagère et de soins médicaux ou obstétriciens. Les religieuses ont donc contribué à la diffusion d'une conception de la féminité, articulant la figure de la bonne chrétienne, de la bonne épouse et de la bonne mère, mais aussi des rapports sociaux de genre. La grande diffusion des cartes postales missionnaires dans l'entre-deux-guerres oblige, en outre, à détailler les stratégies visuelles des entreprises missionnaires et le rôle joué par les images du travail féminin dans cette propagande. Le corpus étudié témoigne ainsi de l'ambivalence des rencontres missionnaires, entre émancipation et domination.

Based on a corpus of missionary postcards dating from the 1920s and 1930s and devoted to West Africa, this article aims to analyze the transmission of a certain conception of women's work in the colonial missionary context. The women at work, in this article, are therefore both missionary women and African women, because work is precisely what brings them together in images, or even in their experience of femininity. In addition to their mission of evangelization, an essential part of the activity of the nuns was to transmit a body of knowledge and know-how in manual work, domestic work and medical or obstetric care. The nuns thus contributed to the diffusion of a conception of femininity articulating the figure of the good christian, the good wife and the good mother, and of the social gender relations. The large circulation of missionary postcards in the inter-war period also made it necessary to detail the visual strategies of missionary enterprises and the role played by the images of women's work in this propaganda. The studied corpus underlines the ambivalence of missionary encounters, between emancipation and domination.

\section{INDEX}

Mots-clés : missions catholiques, travail féminin, cartes postales, enseignement ménager, Afrique de l'Ouest

Keywords : catholic missions, women's work, domestic work, postcards, West Africa

\section{AUTEUR}

\section{JULIEN BONDAZ}

Julien Bondaz est ethnologue, maître de conférences au département d'anthropologie de l'université Lyon 2 et chercheur au Laboratoire d'Anthropologie des Enjeux Contemporains (FRE 2002, CNRS et Université Lyon 2). Outre les enquêtes ethnographiques qu'il mène en Afrique de l'Ouest depuis 2005, il conduit également des recherches sur l'histoire de l'ethnologie et sur l'anthropologie visuelle à la fin de la période coloniale. Il est l'auteur de nombreuses publications 
et a collaboré ou collabore avec plusieurs institutions muséales (musée du quai Branly-Jacques Chirac, musée des Confluences, Musée africain de Lyon, musée Albert-Kahn...) 